\title{
Use of a Clinical Pathway To Facilitate the Translation and Utilization of AHRQ EPC Report Findings
}

FY2018 Dissemination Pilot: Early Diagnosis, Prevention, and Treatment of Clostridium difficile 


\section{Use of a Clinical Pathway To Facilitate the Translation and Utilization of AHRQ EPC Report Findings}

FY2018 Dissemination Pilot: Early Diagnosis, Prevention, and Treatment of Clostridium Difficile

Prepared for:

Agency for Healthcare Research and Quality

U.S. Department of Health and Human Services

5600 Fishers Lane

Rockville, MD 20857

www.ahrq.gov

Contract No. 290-2015-00005-I

Prepared by:

ECRI Institute-Penn Medicine Evidence-based Practice Center

Philadelphia, PA

Investigators:

E. Flores, Ph.D., R.N.

J. Jane Jue, M.D., M.Sc.

Gina Giradi, M.S.

K. Schoelles, M.D., S.M.

C.A. Umscheid, M.D., M.S.C.E.

AHRQ Publication No. 19-EHC002-EF

December 2018 


\section{Key Messages}

\section{Pilot Project Purpose}

Clinical pathways are one method of integrating evidence into local health care settings and structures. The purpose of this ECRI Institute - Penn Medicine EPC project was to evaluate the feasibility of using the updated 2016 AHRQ EPC report on the Early Diagnosis, Prevention, and Treatment of Clostridium difficile in our standard clinical pathway and dissemination process to develop an evidence-based clinical pathway for the treatment of Clostridium difficile infection (CDI) in the acute care setting.

\section{Key Messages}

- $\quad$ The AHRQ EPC report provided value by presenting an overview of the most updated evidence for antibiotic treatment for our stakeholder group, which included clinical and non-clinical members. We found that the AHRQ EPC Report served as an evidence standard and was particularly valuable given that the existing guidelines were outdated. Discrepancies found between the more recent AHRQ EPC report and the dated guidelines prompted critical discussions regarding the comparative efficacy of available treatments.

- This AHRQ EPC report would have been more useful in our pathway development process if it included a summary of recommendations from recent guidelines. The lack of a guideline synthesis reduced our ability to use this source as the sole resource to develop a clinical pathway.

- Access to up to date AHRQ EPC reports can be a useful resource to inform pathway development in the context of outdated guidelines. We recommend that AHRQ prioritize updating reports that are of particular value to health systems and develop communication channels with societies and professional organizations to alert them to newly published EPC reports, especially when findings have changed from previous standards of care.

- Additional recommendations for the AHRQ EPC program include (1) facilitating the sharing of clinical pathways across health systems by providing a moderated platform to host evidence-based clinical pathways from health systems or other organizations and (2) developing a methodology or grading tool for assessing the trustworthiness of clinical pathways. 
This report is based on research conducted by the ECRI Institute-Penn Medicine Evidence-based Practice Center (EPC) under contract to the Agency for Healthcare Research and Quality (AHRQ), Rockville, MD (Contract No. 290-2015-00005-I). The findings and conclusions in this document are those of the authors, who are responsible for its contents; the findings and conclusions do not necessarily represent the views of AHRQ. Therefore, no statement in this report should be construed as an official position of AHRQ or of the U.S. Department of Health and Human Service

\section{None of the investigators have any affiliations or financial involvement that conflicts with the material presented in this report.}

The information in this report is intended to help health care decisionmakers—patients and clinicians, health system leaders, and policymakers, among others-make well-informed decisions and thereby improve the quality of health care services. This report is not intended to be a substitute for the application of clinical judgment. Anyone who makes decisions concerning the provision of clinical care should consider this report in the same way as any medical reference and in conjunction with all other pertinent information, i.e., in the context of available resources and circumstances presented by individual patients.

This report is made available to the public under the terms of a licensing agreement between the author and the Agency for Healthcare Research and Quality. This report may be used and reprinted without permission except those copyrighted materials that are clearly noted in the report. Further reproduction of those copyrighted materials is prohibited without the express permission of copyright holders.

AHRQ or U.S. Department of Health and Human Services endorsement of any derivative products that may be developed from this report, such as clinical practice guidelines, other quality enhancement tools, or reimbursement or coverage policies, may not be stated or implied.

Persons using assistive technology may not be able to fully access information in this report. For assistance contact EPC@ahrq.hhs.gov.

Suggested citation: Flores E, Jue JJ, Giradi G, Schoelles K, Umscheid CA. Use of a Clinical Pathway to Facilitate the Translation and Utilization of AHRQ EPC Report Findings. Methods Research Report. (Prepared by the ECRI Institute-Penn Medicine Evidence-based Practice Center under Contract No. 290-2015-0005-I.) AHRQ Publication No. 19-EHC002-EF. Rockville, MD: Agency for Healthcare Research and Quality; December 2018. Posted final reports are located on the Effective Health Care Program search page.

DOI: https://doi.org/10.23970/AHRQEPCMETHENGAGECLINICAL. 


\section{Preface}

The Agency for Healthcare Research and Quality (AHRQ), through its Evidence-based Practice Centers (EPCs), sponsors the development of evidence reports and technology assessments to assist public- and private-sector organizations in their efforts to improve the quality of health care in the United States. The reports and assessments provide organizations with comprehensive, science-based information on common, costly medical conditions and new health care technologies and strategies. The EPCs systematically review the relevant scientific literature on topics assigned to them by AHRQ and conduct additional analyses when appropriate prior to developing their reports and assessments.

To improve the scientific rigor of these evidence reports, AHRQ supports empiric research by the EPCs to help understand or improve complex methodologic issues in systematic reviews. These methods research projects are intended to contribute to the research base in and be used to improve the science of systematic reviews. They are not intended to be guidance to the EPC program, although may be considered by EPCs along with other scientific research when determining EPC program methods guidance.

AHRQ expects that the EPC evidence reports and technology assessments will inform individual health plans, providers, and purchasers as well as the health care system as a whole by providing important information to help improve health care quality. The reports undergo peer review prior to their release as a final report.

If you have comments on this Methods Research Project they may be sent by mail to the Task Order Officer named below at: Agency for Healthcare Research and Quality, 5600 Fishers Lane, Rockville, MD 20857, or by email to epc@ahrq.hhs.gov.

Gopal Khanna, M.B.A.

Director

Agency for Healthcare Research and Quality

Stephanie Chang, M.D., M.P.H.

Director

Evidence-based Practice Center Program

Center for Evidence and Practice Improvement

Agency for Healthcare Research and Quality
Arlene Bierman, M.D., M.S.

Director

Center for Evidence and Practice Improvement Agency for Healthcare Research and Quality

Kim Marie Wittenberg, M.A.

Task Order Officer

Center for Evidence and Practice Improvement Agency for Healthcare Research and Quality 


\section{Acknowledgments}

The authors gratefully acknowledge the following individuals at ECRI Institute: Allison Gross, M.S., M.L.S., Helen Dunn, Katherine Donahue and Jennifer Maslin, and AHRQ: Amanda Borsky, Dr.P.H., M.P.P., for their contributions to this project. 


\section{Use of a Clinical Pathway To Facilitate the Translation and Utilization of AHRQ EPC Report Findings}

\section{Structured Abstract}

Background. Clinical pathways are one method of promoting the uptake of evidence into clinical practice. The ECRI Institute-Penn Medicine EPC incorporated the updated 2016 AHRQ EPC report on Early Diagnosis, Prevention, and Treatment of Clostridium difficile in the development of a clinical pathway for treatment of Clostridium difficile infection (CDI) in the acute care setting. This EPC report was selected as it complements other CDI initiatives currently being undertaken at the University of Pennsylvania Health System (UPHS). The objective of this pilot project was to assess the incremental value of including AHRQ EPC report findings in the pathway development process, as well as examine the value these reports may contribute to the process, and the time and resource requirements for this activity.

Methods. UPHS is a multicenter academic health care system in the Philadelphia region. We recruited a clinical owner and a representative multidisciplinary stakeholder panel to participate in the development of a clinical pathway, including experts from infectious diseases, infection control, antimicrobial stewardship, pharmacy, hospital medicine, and the UPHS CDI initiative, as well as clinical informatics. This process was facilitated by the PennPathways Program Manager and Director of the Penn Medicine Center for Evidence-based Practice (CEP). ECRI Institute was responsible for conducting a rapid evidence review.

CEP used their existing 10-step framework for developing and disseminating clinical pathways across a geographically distributed health system. Steps include:

1. Identifying an engaged clinical owner;

2. Recruiting representative stakeholders;

3. Conducting a rapid review of existing guidelines and pathways;

4. Developing a prototype pathway;

5. Reviewing the rapid review and pathway prototype with stakeholders;

6. Conducting additional rapid reviews as necessary;

7. Updating the pathway using asynchronous feedback by stakeholders as necessary;

8. Quality assurance and finalizing content and meta-data;

9. Developing a messaging strategy and disseminating; and

10. Monitoring utilization and updating.

Steps 4, 7, 9, and 10 are facilitated via a Web-based tool (Dorsata Inc., Washington, DC).

Results. We initiated our evidence review (step 3) with a review of the AHRQ EPC report on CDI infection. We noted that the report lacked a synthesis of existing guidelines and pathwaysproducts that are critical to the standard pathway development process at Penn Medicine. To address this gap, our partners at ECRI Institute conducted a rapid review of recent guidelines and pathways (step 3). We reviewed these two evidence products with the stakeholder group (step 5) and found that the EPC report was beneficial in that it provided a common understanding of the evidence, which was especially useful for stakeholders less familiar with the current evidence. During the stakeholder review, we identified several differences between the EPC report and recommendations from existing guidelines, which prompted important internal discussions 
regarding evidence-based treatment. In this respect, the EPC report served as an evidence standard. The CDI treatment clinical pathway was approved by the clinical stakeholders and disseminated through our PennPathways site on April 16, 2018. As of August 31, 2018, the pathway has been viewed 325 times. Total direct project hours were 331. The two project activities with the highest number of direct hours were the rapid evidence review (272 hours) and pathway development (37 hours). The CDI clinical pathway was also deposited to the CDS Connect website to facilitate dissemination and development of computer readable content across other health systems and settings.

Discussion. This pilot suggests that AHRQ EPC reports can provide value in the process of developing clinical pathways, but that inclusion of guideline recommendation summaries and guideline quality assessments and pathways from professional organizations, governments and major academic medical centers, will be necessary to meet their full potential. Our findings also suggest that providers utilize clinical pathways when available. 


\section{Contents}

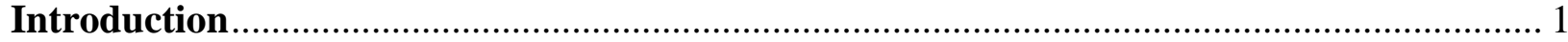

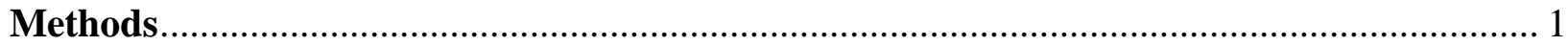

Pathway Development and Dissemination Framework................................................... 1

Technology To Support Pathway Development, Dissemination, and Utilization Assessment.. 2

Rapid Evidence Review To Inform Pathway Development....................................................... 3

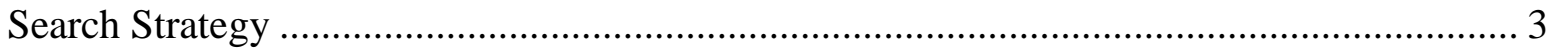

Inclusion and Exclusion Criteria...................................................................................... 3

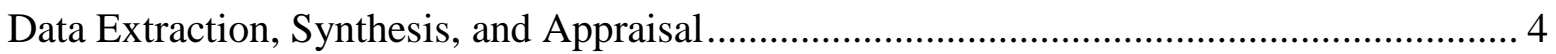

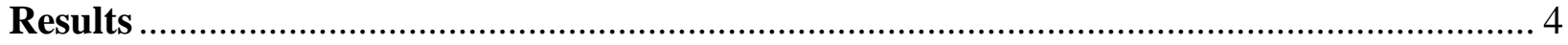

Clinical Owner and Stakeholder Panel .......................................................................... 4

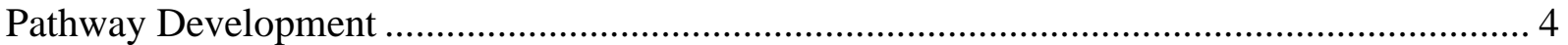

Pathway Dissemination and Assessment ........................................................................... 11

Pathway Development Resource and Time Requirements ..................................................... 16

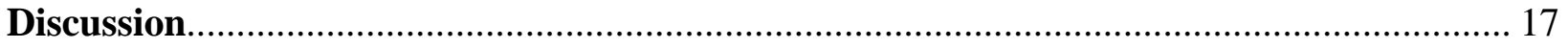

Utility and Applicability for Other Health Systems ………….................................................. 17

Lessons Learned and Applicability for Other EPC Reports ....................................................... 19

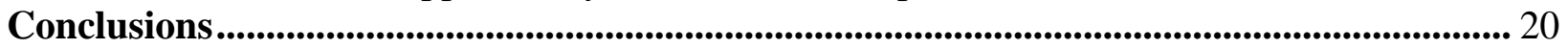

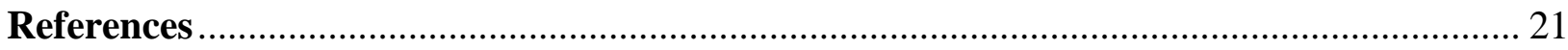

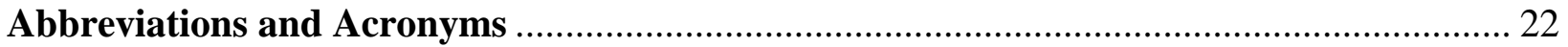

\section{Tables}

Table 1. PICOTS (populations, interventions, comparisons, outcomes, timing, and setting) criteria for including studies in the review .......................................................... 4

Table 2. ECRI Institute - Penn Medicine EPC project roles and responsibilities ........................ 16

Table 3. UPHS clinical pathway development process steps and direct time allocation for pathway development and dissemination

\section{Figures}

Figure 1a. C. difficile treatment pathway prototype, with specific recommendations embedded at the appropriate node, used for stakeholder group review (view of the entire pathway)...

Figure 1b. C. difficile treatment pathway prototype, with specific recommendations embedded at the appropriate node, used for stakeholder group review (enlarged subset of pathway related to treatment of non-severe disease)......

Figure 2a. C. difficile treatment pathway after the initial in-person meeting (entire pathway). IDSA recommendations, which were released after the initial stakeholder review, were embedded at the appropriate step in the pathway to facilitate reviewer comparison of the new IDSA recommendations to the original pathway recommendations.

Figure2b. C. difficile treatment pathway after the initial in-person meeting (enlarged subset of pathway related to treatment of non-severe disease). IDSA recommendations, which were released after the initial stakeholder review, were embedded at the appropriate step in the pathway to facilitate reviewer comparison of the new IDSA recommendations to the original pathway recommendations

Figure 3. C. difficile treatment pathway views over time 
Figure 4a. Final C. difficile infection treatment pathway after stakeholder review and approval (view of entire pathway)

Figure 4b. Final C. difficile infection treatment clinical pathway after review and approval from the stakeholder group (enlarged subset of the pathway)...............................................13

Figure 4c. Final C. difficile infection treatment clinical pathway after review and approval from the stakeholder group (enlarged subset of the pathway).

Figure 4d. Final C. difficile infection treatment clinical pathway after review and approval from the stakeholder group (enlarged subset of the pathway)...............................................15

\section{Appendixes}

Appendix A. University of Pennsylvania Health System Guidelines, Pathways, and Algorithms Standard Medline Search Methods

Appendix B. PennPathways Online Library (subset) and Example Pathway

Appendix C. PennPathways Mobile Application

Appendix D. PennPathways Analytics Dashboard

Appendix E. CEP Trustworthy Guideline Appraisal Tool

Appendix F. Modified AMSTAR Scale

Appendix G. IDSA 2018 Clinical Practice Guideline Recommendation Differences as Noted in the Pathway

Appendix H. Final CDI Clinical Pathway

Appendix I. Screen Savers Used for Messaging the C. difficile Treatment Pathway

Appendix J. Clinical Pathway Integration into the Electronic Health Record (Phase One)

Appendix K. Rapid Evidence Review 


\section{Introduction}

In March 2017, the University of Pennsylvania Heath System (UPHS) launched an initiative aimed at reducing Clostridium difficile infections (CDI). Building on work already conducted on Clostridium difficile testing, the ECRI Institute - Penn Medicine EPC used the updated 2016 AHRQ EPC report on Early Diagnosis, Prevention, and Treatment of Clostridium difficile ${ }^{1}$ as input in the development of a clinical pathway for CDI treatment. The objective of this project was to assess the incremental value of including EPC report findings in the pathway development process, as well as examine how the EPC report may have provided more value in this process, and the time and resource requirements for this process, all information that may be useful to other health care systems.

\section{Methods}

\section{Pathway Development and Dissemination Framework}

In 2016, the PennPathways Program was established within the UPHS Center for Evidencebased practice (CEP), with the goal of facilitating the translation of evidence-based recommendations into clinical practice across our geographically distributed health care system. ${ }^{2}$ CEP has developed a 10-step framework, based on the Knowledge-to-Action (KTA) ${ }^{3}$ and ADAPTE $^{4}$ frameworks, to develop and disseminate clinical pathways. ${ }^{2}$ Our framework steps are outlined below.

Step 1. Identify an engaged clinical leader. This should be an individual with deep clinical experience who is also a decisionmaker. This role is responsible for being the project lead and champion, as well as defining the problem being addressed by the clinical pathway and pathway scope.

Step 2. Recruit a small but representative stakeholder group. This group will be responsible for developing the pathway, including assessing available guidelines, pathways, and other evidence and providing feedback on the translation of this evidence into a clinical pathway to be used in the local setting. ${ }^{5}$ Conduct an exercise with the clinical leader to identify key colleagues from across the organization who are critical to clinical pathway design, as well as development of the dissemination strategy. Ensure that nursing, pharmacy, laboratory services, and the emergency department are represented as needed. Early inclusion of those impacted most by the clinical pathway will be critical for dissemination and implementation.

Step 3. Conduct a rapid evidence review. A rapid review of clinical practice guidelines and pathways should be conducted, with a focus on content from the National Guideline Clearinghouse (NGC), ${ }^{i}$ the National Institute for Health and Care Excellence (NICE) Evidence Search, Medline, EMBASE, and Cochrane, as well as clinical specialty societies and large health care system pathways. Our center has developed standard approaches to searching for pathways (Appendix A). Appraisal methods, such as the guidelines standards published by the Institute of Medicine, ${ }^{6}$ should be used to help assess the rigor of identified guidelines.

Step 4. Build a prototype pathway based on the rapid review. Pathways found during the evidence review phase should serve as the foundation for developing the pathway prototype. We

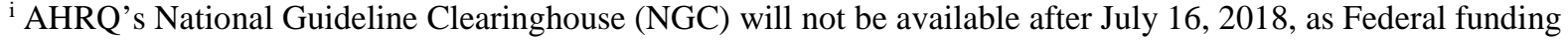
through AHRQ will no longer be available to support the NGC as of that date. AHRQ is receiving expressions of interest from stakeholders interested in carrying on NGC's work. It is not clear at this time, however, when or if NGC (or a resource similar to NGC) will be online again. (https://www.guideline.gov/home/announcements)
} 
recommend that this work be completed by a program manager or clinical pathway facilitator (in our case, this work is completed by the PennPathways Program Manager). A summary of differences in recommendations across evidence products can be embedded within the pathway prototype to facilitate discussion with the key stakeholders. This effort will help jumpstart discussion at the in-person meeting of the key stakeholder group.

Step 5. Review the rapid evidence review and prototype pathway with the key stakeholders during an initial in-person meeting. Plan for at least one in-person meeting with the stakeholder group to review the evidence and the prototype pathway and refine the pathway for the local setting. During this process, additional clinical questions may arise that may require additional targeted reviews of existing guidelines and published literature. After this meeting, the pathway program manager or clinical pathway facilitator should update the pathway with changes agreed upon in the meeting and note areas for follow up. We recommend embedding questions for follow up directly into the pathway.

Step 6. Perform additional rapid reviews as necessary to inform specific decisions. Conduct targeted rapid reviews for clinical questions that arose during the initial review.

Step 7. Asynchronously refine the clinical pathway. To expedite the review process, refine the pathway asynchronously using available software, such as email or other collaboration tools. At UPHS, we use a Web-based platform for online collaboration, with overall management of the process by the pathway program manager. Follow up questions that require stakeholder input are embedded into the pathway. Strict version control should be maintained as the pathway is iteratively refined.

Step 8. Conduct a quality assurance review and finalize pathway content and design. The final pathway version must be approved by all key stakeholders before the pathway can be published for use by the wider health system audience. We recommend publishing key meta-data (Appendix B) with the pathway, such as the pathway owner, stakeholders, release date, key metrics and outcomes, and a description.

Step 9. Develop a messaging plan and disseminate the pathway. Work with the stakeholder team to develop a messaging plan. Ensure that different clinical user types are taken into account and tailor the plan accordingly. Use available software to make content available across the clinical audience. At UPHS, we use a Web-based platform for online collaboration. (See the Supporting Technology section below.)

Step 10. Develop monitoring and maintenance plans. Monitor pathway utilization using available software (see Supporting Technology below). In the maintenance phase, pathways and their supporting evidence should be periodically reviewed to identify changes in evidence or processes of care. At UPHS, pathway content is reviewed every three years. ${ }^{7}$

\section{Technology To Support Pathway Development, Dissemination, and Utilization Assessment}

In 2016 UPHS implemented a Web-based platform for asynchronous collaboration, development, dissemination and monitoring of pathway content across our health care system (Dorsata, Inc., Washington, DC). ${ }^{2}$ Content is viewable via the Internet (Appendix B) and a mobile app (Appendix C), and can also be downloaded for offline use. This platform stores key pathway metadata, such as evidence-based references, versioning information, and the information for the clinical owner of the pathway, as well as the stakeholder members that developed the pathway (Appendix B). Pathway usage is monitored by pathway owners and program administrators in real-time via the platform analytics dashboards (Appendix D). 
Analytics includes pathway views over time. The platform also provides a means for pathway users to provide instant electronic feedback to clinical owners and administrators (Appendix B).

\section{Rapid Evidence Review To Inform Pathway Development}

In this project, the AHRQ EPC report ${ }^{1}$ was positioned as the main evidence review used to inform pathway development. However, because our pathway development framework utilizes existing guidelines and pathways (CEP framework step three), and because the AHRQ EPC report ${ }^{1}$ did not systematically review existing guidelines and pathways, an additional rapid review was conducted to identify and synthesize guidelines and pathways. In addition, because the search dates for the report ended in 2015, the additional rapid review was used to identify and incorporate more recent primary evidence not included in the original EPC report. The following section outlines the strategy that was used by ECRI Institute to conduct the additional rapid review.

\section{Search Strategy}

In accordance with established systematic review protocols, ECRI Institute conducted a rapid synthesis of recent guidelines and pathways and included RCTs as a focused update of the treatment-focused portions of the AHRQ EPC report on Early Diagnosis, Prevention, and Treatment of Clostridium difficile, for the management of patients with acute Clostridium difficile (C. difficile) colitis. ${ }^{1}$ Specifically, we focused on the treatment portions of Key Question (KQ)3 and KQ4:

KQ3: What are the comparative effectiveness and harms of different antibiotic treatments?

KQ4: What are the effectiveness and harms of other interventions?

Starting from the last search date noted in the report, searches for the rapid review covered the literature published in English and conducted in OECD countries, from April 2015 to the present for original studies, and January 2010 to the present for guidelines and pathways as these were not included specifically in the original AHRQ EPC report. ${ }^{1}$ Databases included Embase.com (Medline/EMBASE combined) and PubMed (In Process/Publisher subsets) as well as grey literature searches including Google, National Guideline Clearinghouse, Web sites of professional organizations, UpToDate ${ }^{\circledR}$, DynaMed ${ }^{\circledR}$ and ClinicalKey ${ }^{\circledR}$. Other mechanisms used to retrieve additional relevant information included review of bibliographies/reference lists from peer-reviewed and gray literature. (Gray literature consists of reports, studies, articles, and monographs produced by Federal and local government agencies, private organizations, educational facilities, consulting firms, and corporations. These documents do not appear in the peer-reviewed journal literature.) While using a similar strategy to the AHRQ report, we not only updated the AHRQ searches, but we also enhanced the searches, including the grey literature searches, with this rapid review.

\section{Inclusion and Exclusion Criteria}

We followed the PICOTS framework in developing inclusion and exclusion criteria (Table 1). Because of the focused nature of the project and rapid review, we also tailored the inclusion and exclusion criteria for the project. We limited the patient population to those in a hospital inpatient setting, given the target and roll out of the pathway. 
Table 1. PICOTS (populations, interventions, comparisons, outcomes, timing, and setting) criteria for including studies in the review

\begin{tabular}{|l|l|}
\hline Category & Criteria \\
\hline Participants & $\begin{array}{l}\text { Adult patients (age >18yo) with acute C. difficile colitis in the inpatient setting, including initial, } \\
\text { recurrent, relapsed, or refractory infection. Exclude outpatient and extended care setting. }\end{array}$ \\
\hline Interventions & $\begin{array}{l}\text { Drug therapy, fecal microbiota transplantation, probiotics, and other approaches to the } \\
\text { treatment of acute C. difficile colitis in the inpatient setting. Exclude prevention and therapies } \\
\text { not likely to be available on US market within 1 year. }\end{array}$ \\
\hline Comparisons & Any, including antibiotic treatments or placebo, usual care, active care, or none. \\
\hline Outcomes & $\begin{array}{l}\text { Mortality, recurrence (study-defined), clearance or cure (study-defined), complications, } \\
\text { symptom resolution (study-defined), CDI-related colectomy rate, harms (e.g., delayed } \\
\text { treatment response). }\end{array}$ \\
\hline Timing & Acute or recurrent infection \\
\hline Setting & Acute inpatient setting. Exclude outpatient and extended care setting. \\
\hline
\end{tabular}

CDI: Clostridium difficile infections

\section{Data Extraction, Synthesis, and Appraisal}

Literature search results were initially screened for relevancy by a medical librarian. Relevant abstracts were then screened against the inclusion and exclusion criteria in duplicate. All disagreements were $<10 \%$ of total screened and were resolved by consensus discussion between the two original screeners. Studies that appeared to meet the inclusion criteria were retrieved in full and screened by the lead screener against the inclusion and exclusion criteria.

Findings were synthesized using descriptive evidence tables and included tables of relevant guideline recommendations and relevant pathways.

Guidelines were assessed using the CEP Trustworthy Guideline scale (Appendix E), ${ }^{8}$ while systematic reviews were assessed using a modified AMSTAR checklist ${ }^{9}$ (Appendix F).

\section{Results}

\section{Clinical Owner and Stakeholder Panel}

We recruited a clinical owner and representative multidisciplinary stakeholder panel to participate in the development and dissemination of a clinical pathway for CDI treatment in our health system, which are steps in our standard pathway development and dissemination approach (CEP framework steps one and two). Representation depends on the clinical topic; for this project, we included experts from infectious diseases, infection control, antimicrobial stewardship, pharmacy, hospital medicine, the UPHS CDI initiative, as well as clinical informatics. The development and dissemination process was facilitated by the PennPathways Program Manager and Director of the Penn Medicine Center for Evidence-based Practice (CEP).

\section{Pathway Development}

The AHRQ EPC report ${ }^{1}$ was useful as a conceptual foundation for the state of the evidence on the topic. Seeking to update the report, the ECRI Institute EPC staff conducted a rapid evidence review of existing guidelines and pathways (CEP framework step three), a key input in the development of the pathway prototype. After a period of review and clarification with ECRI Institute, the PennPathways Program Manager developed a prototype pathway based on three of the seven existing pathways identified and recommendations from five of the eight existing guidelines, as well as evidence summarized by the EPC report. ${ }^{1}$ The prototype was then 
reviewed clinically by the Director of CEP (CEP framework step four). Guideline recommendations enumerated in the ECRI Institute report, especially discordant recommendations identified across the guidelines, were embedded within the pathway prototype in preparation for review by the stakeholder panel (Figure 1a and 1b). 
Figure 1a. C. difficile treatment pathway prototype, with specific recommendations embedded at the appropriate node, used for stakeholder group review (view of the entire pathway)

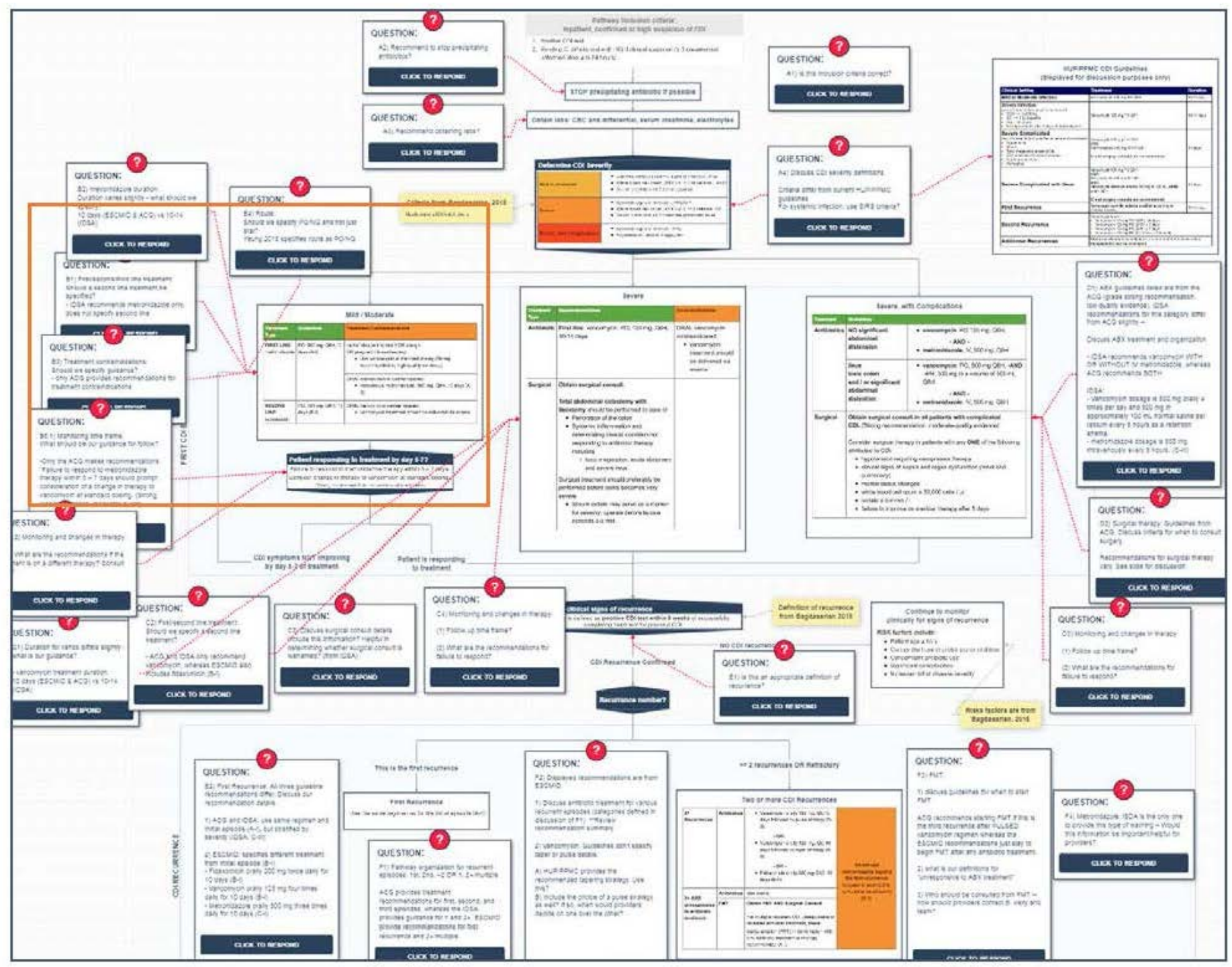


Figure 1b. C. difficile treatment pathway prototype, with specific recommendations embedded at the appropriate node, used for stakeholder group review (enlarged subset of pathway related to treatment of non-severe disease)

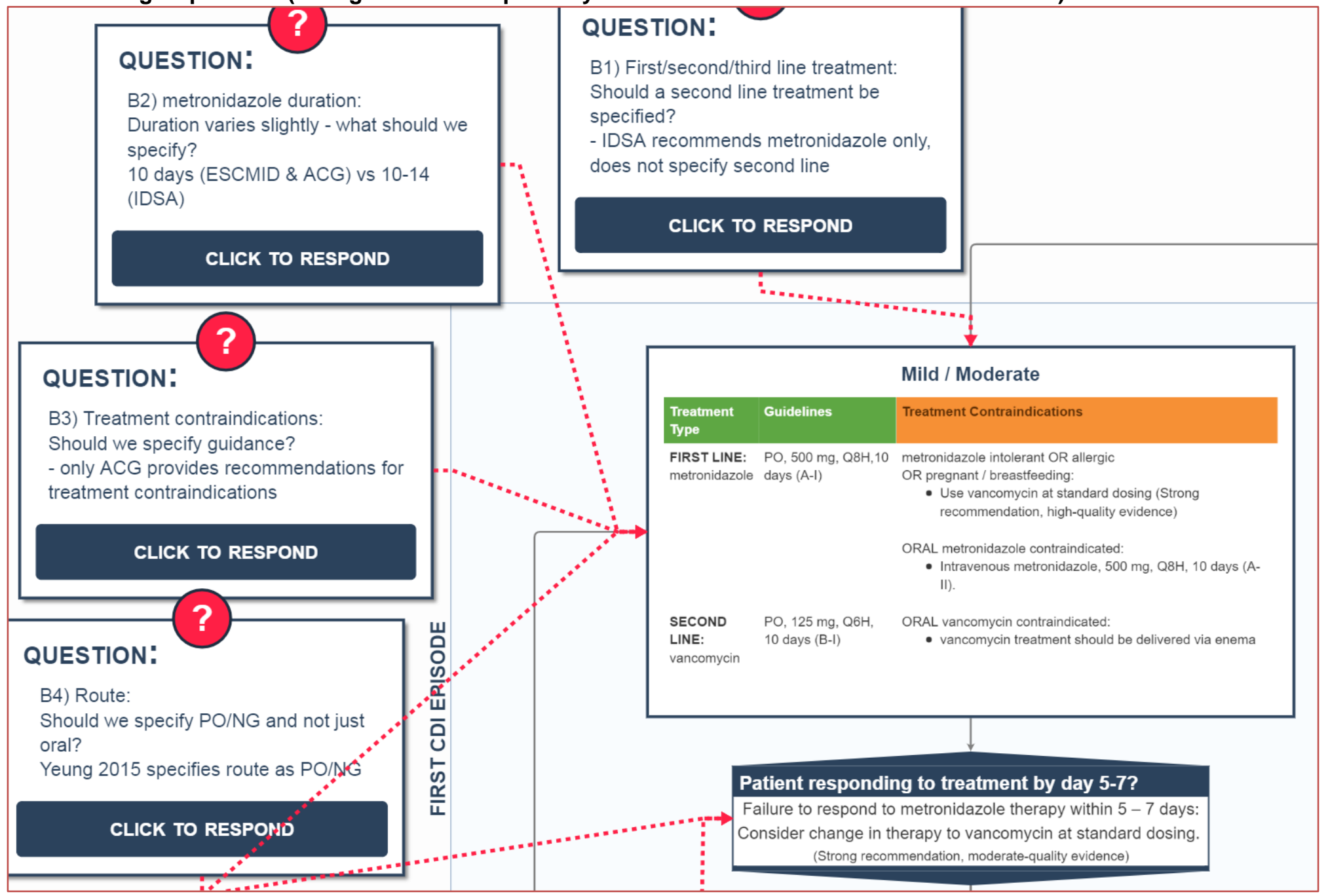


We convened a 2-hour, in-person stakeholder meeting on January 29, 2018 to review the AHRQ EPC report, ${ }^{1}$ the ECRI Institute rapid review, and the pathway prototype (CEP framework step five). We initiated this meeting with a review of results from the EPC report. ${ }^{1}$ We focused our review on Tables 6 and 7 (pages 17-22) and Appendix Figures G16-G28 in the 2016 EPC report as these tables presented information in a format easily interpreted by the diverse stakeholder group. We found that these report sections served to provide an important baseline understanding of the evidence for the stakeholder members. We next reviewed the prototype pathway, referencing the ECRI Institute rapid review as needed. In the course of the review, the group identified three areas that required an additional targeted evidence review by ECRI Institute, as they were not specifically addressed in the draft rapid review or the 2016 EPC report, ${ }^{1}$ and were considered critical to the development of the pathway. Follow up topics for ECRI Institute included (1) identifying guideline recommendations for the appropriate imaging (e.g., abdominal CT, x-ray) in the context of suspected CDI and when such might be warranted, (2) guideline recommendations for vancomycin taper strategies for those with multiple CDI recurrences, and (3) guideline recommendations regarding use of intravenous metronidazole if oral metronidazole is not tolerated. In an attempt to factor patient costs into treatment decisions, the pharmacist was responsible for following up on the outpatient cost of oral vancomycin for a first occurrence of C. difficile. At the end of this meeting, the PennPathways Program Manager distributed an email summarizing next steps for the asynchronous review (CEP framework step seven) and topics requiring additional follow-up.

ECRI Institute reassessed the guidelines and pathways originally included in the draft of their rapid review and updated their report as appropriate (CEP framework step six). With regard to imaging studies, ECRI found general recommendations, but the recommendations did not provide useful direction in terms of timing and type of study. ECRI found four vancomycin taper strategies and updated their report accordingly. Lastly, ECRI did not find information that addressed differences in tolerance between intravenous and oral metronidazole. The pharmacist was unable to find specific cost information on outpatient costs for oral vancomycin, as this is dependent on each individual insurance plan and the patients' specific tier of coverage in those plans.

Experts in the meeting noted that the Infectious Diseases Society of America (IDSA) would soon publish an updated guideline for C. difficile treatment, so the Director of CEP contacted IDSA through our guideline contacts, who alerted us to the guideline release date and forwarded the new guideline on February 15, 2018. This new guideline was issued during the asynchronous review phase (CEP framework step seven) for this project. Stakeholder members were alerted to the availability of the new guideline and were informed that the pathway would be updated with the most recent recommendations. ECRI also updated their rapid evidence review to include these new guideline recommendations and the PennPathways Program Manager reviewed the pathway prototype to identify any differences between the new guideline and our treatment recommendations. Differences were reviewed with the Director of CEP and an updated pathway was shared with the stakeholders on February 28, 2018 (Figures 2a and 2b). IDSA recommendations were noted directly in the pathway at the relevant step (a full list of differences can be found in Appendix G). Stakeholders were asked to respond to the revisions by March 12, 2018. 
Figure 2a. C. difficile treatment pathway after the initial in-person meeting (entire pathway). IDSA recommendations, which were released after the initial stakeholder review, were embedded at the appropriate step in the pathway to facilitate reviewer comparison of the new IDSA recommendations to the original pathway recommendations

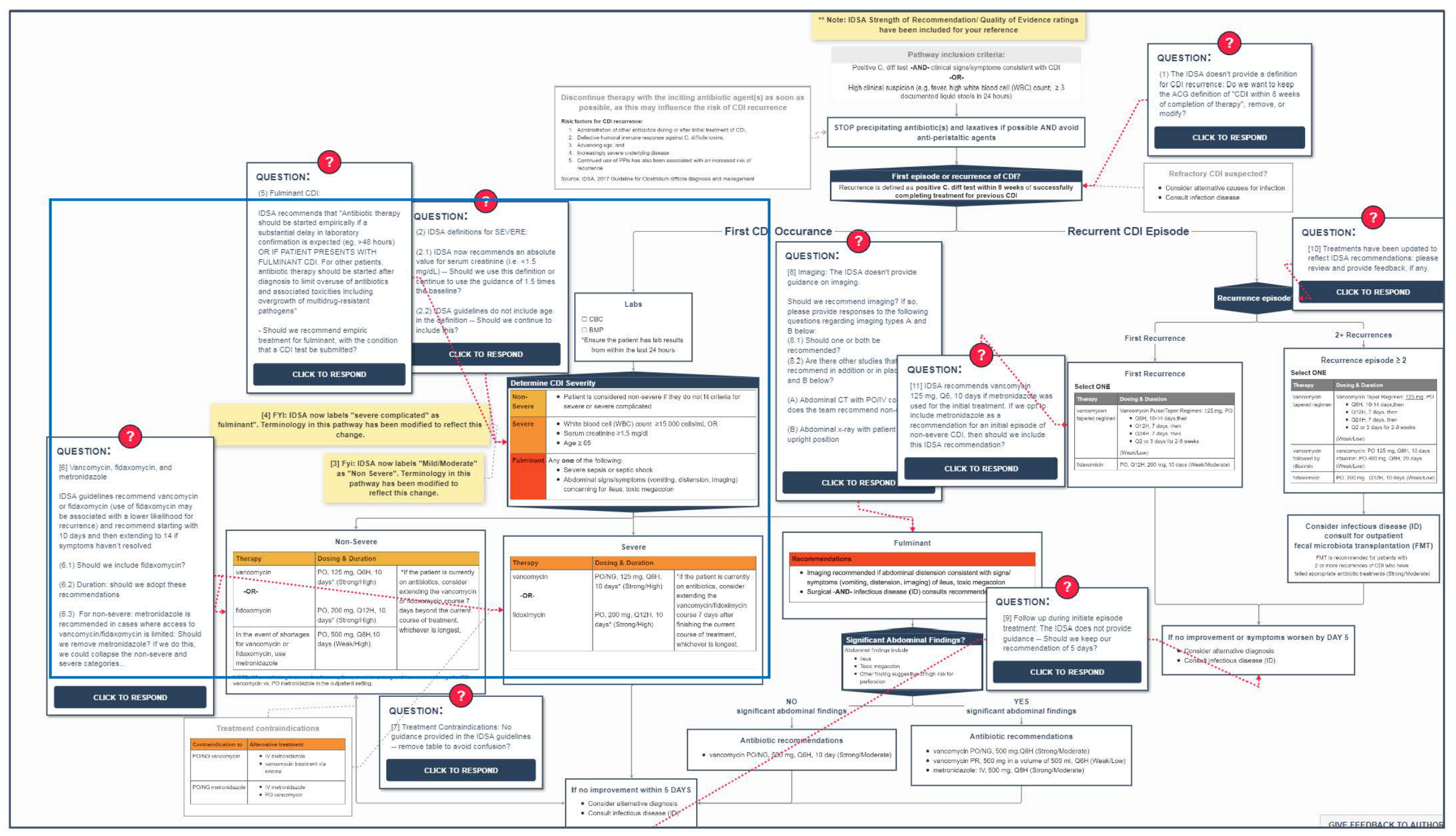


Figure2b. C. difficile treatment pathway after the initial in-person meeting (enlarged subset of pathway related to treatment of non-severe disease). IDSA recommendations, which were released after the initial stakeholder review, were embedded at the appropriate step in the pathway to facilitate reviewer comparison of the new IDSA recommendations to the original pathway recommendations

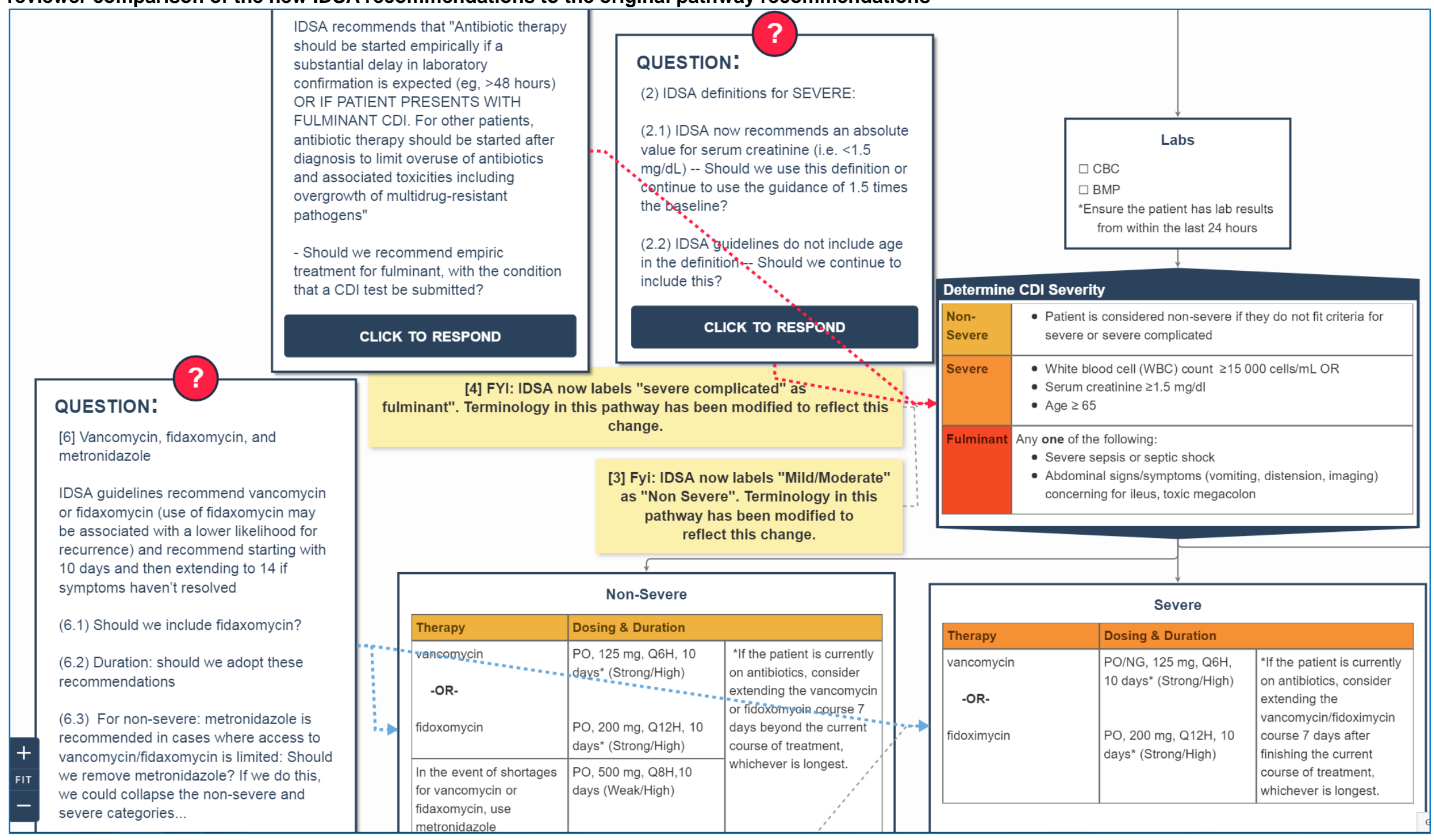


Following the release of the revised IDSA guideline, UPHS underwent a review of their antimicrobial treatment guidelines for Clostridium difficile Associated Diarrhea. The updated UPHS guidelines were reviewed and approved by the UPHS Pharmacy and Therapeutic Committee on April 4, 2018. The pathway was updated to reflect the recommendations provided in the UPHS guidelines and underwent one final round of asynchronous review with stakeholders. The pathway was finalized on April 14, 2018 (Figure 4a-4d). Consensus was achieved on all clinical questions.

\section{Pathway Dissemination and Assessment}

The final CDI treatment clinical pathway (Appendix H) was posted to our PennPathways site on April 16, 2018. Our communication strategy involved using screensavers circulated on desktops across the health system to publicize the pathway (Appendix I). Screen savers were deployed across three hospitals on May 1, 2018. Our assessment included measuring pathway adoption, which we defined as the intention, initial decision, or action to try or employ an innovation or evidence-based practice. ${ }^{10}$ This outcome was assessed by measuring provider views on our clinical pathways analytics dashboard. As of August 31, 2018, the pathway had been viewed 325 times (Figure 3).

Figure 3. C. difficile treatment pathway views over time Clostridium difficile (C.diff) Infection Treatment Pathway view Document

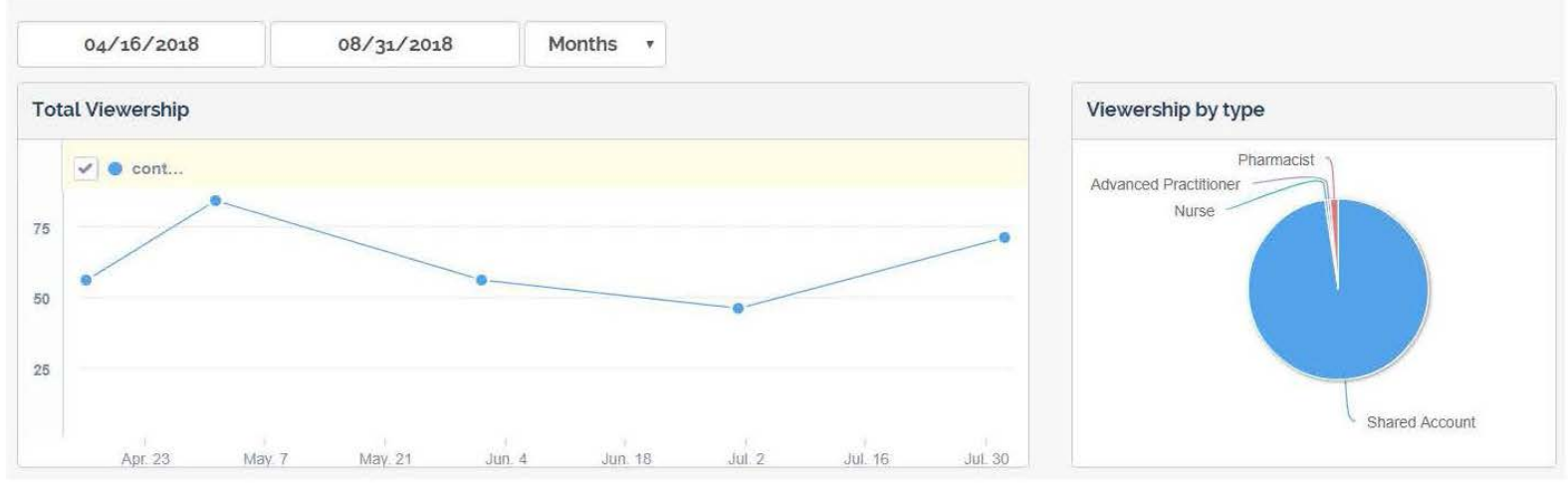


Figure 4a. Final C. difficile infection treatment pathway after stakeholder review and approval (view of entire pathway)

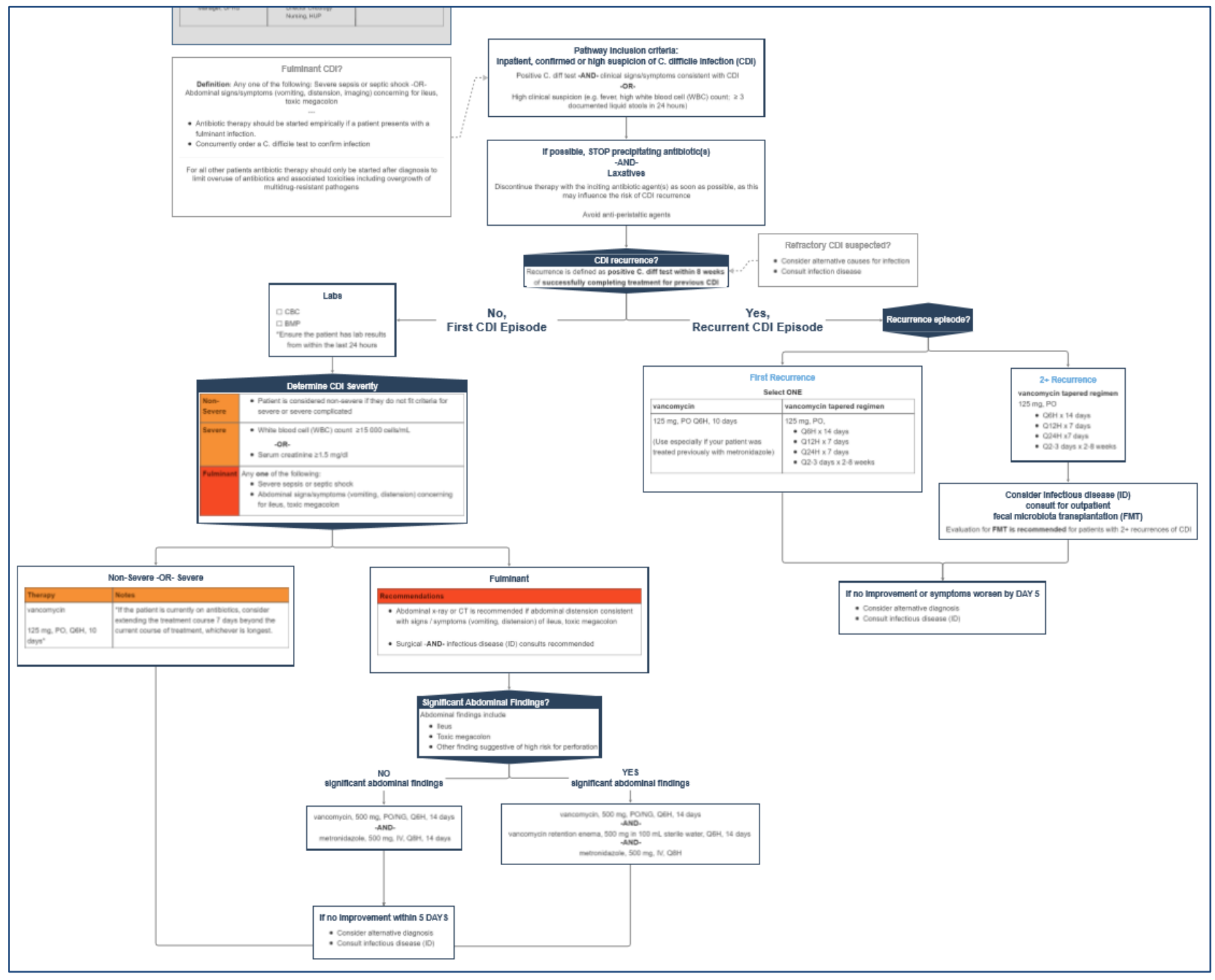


Figure 4b. Final C. difficile infection treatment clinical pathway after review and approval from the stakeholder group (enlarged subset of the pathway)

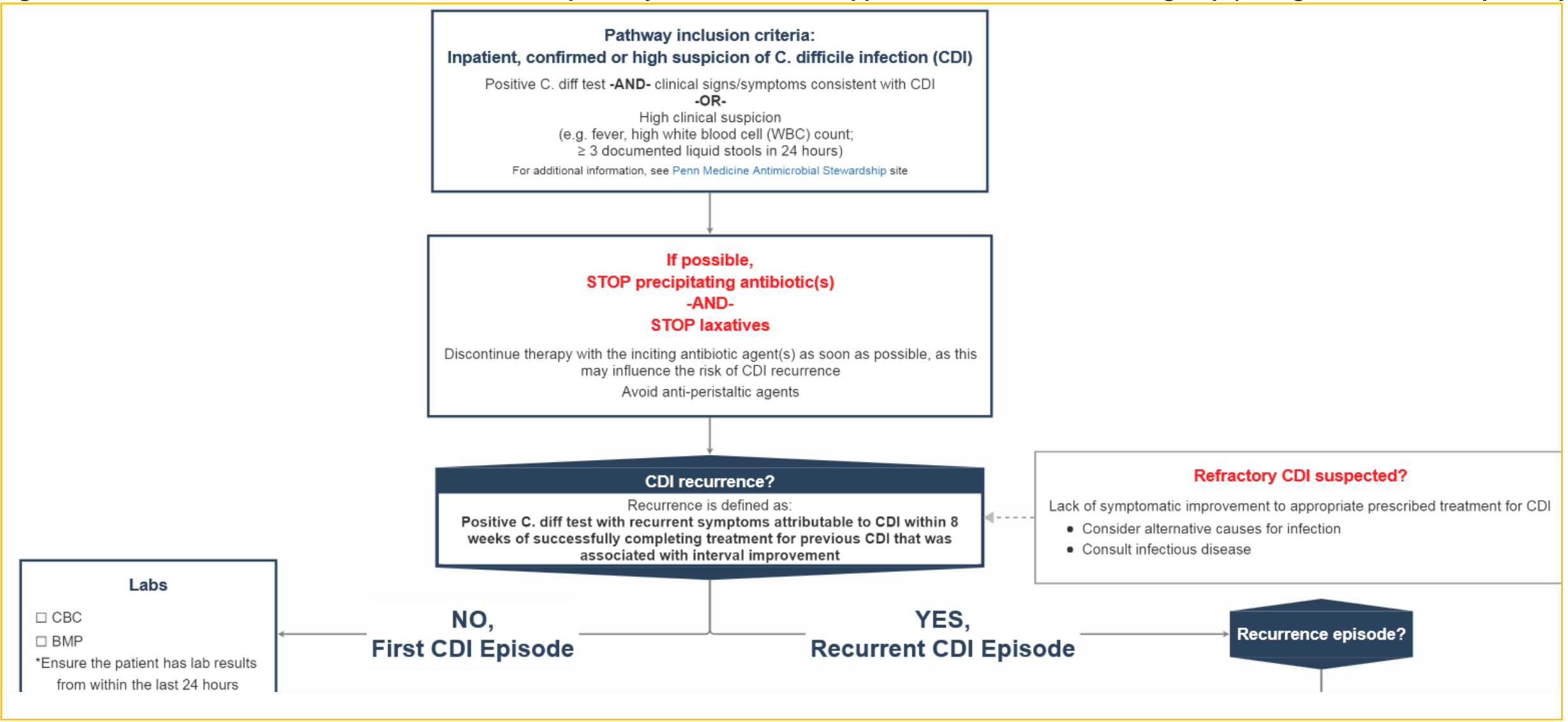


Figure 4c. Final C. difficile infection treatment clinical pathway after review and approval from the stakeholder group (enlarged subset of the pathway)

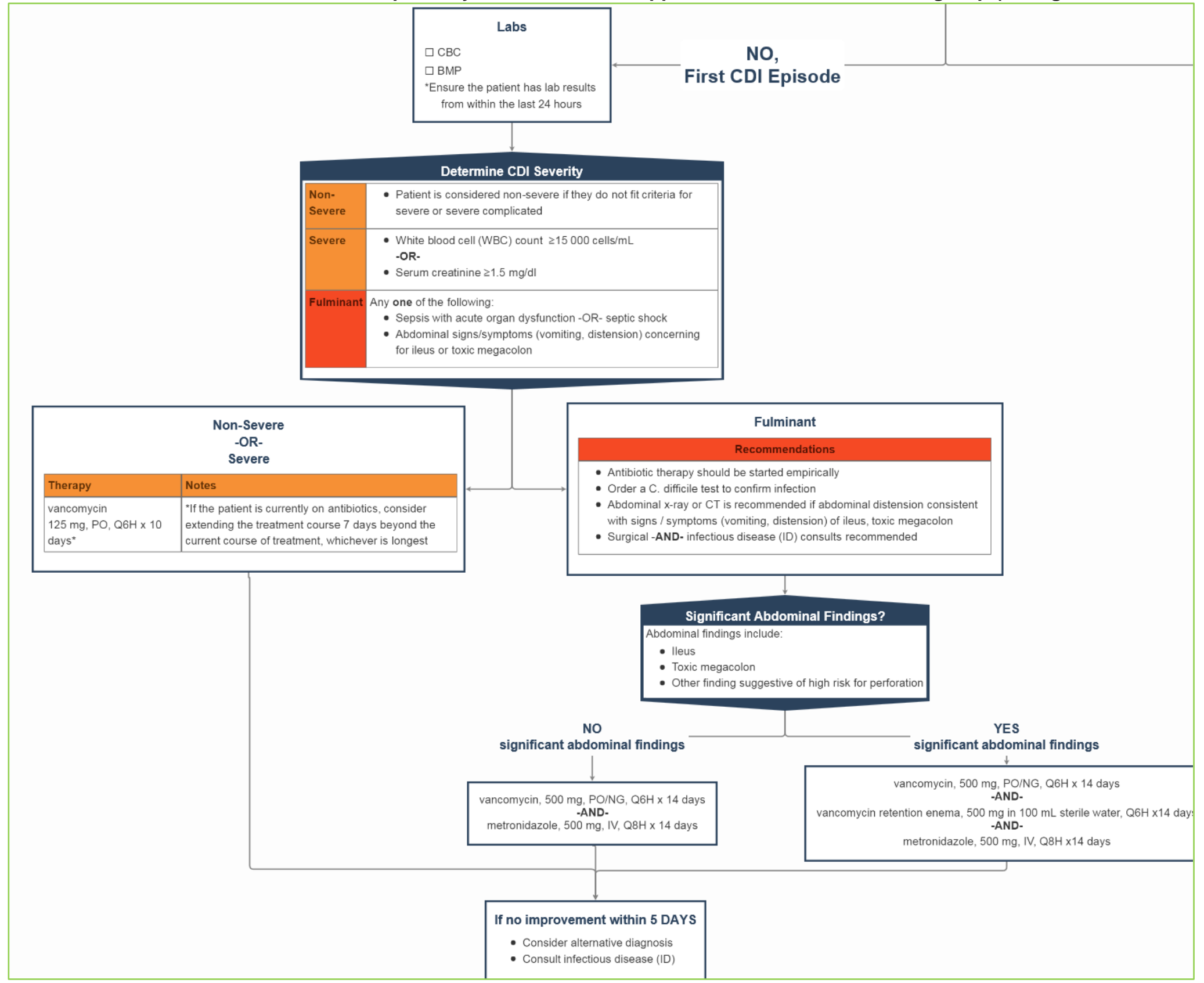


Figure 4d. Final C. difficile infection treatment clinical pathway after review and approval from the stakeholder group (enlarged subset of the pathway)

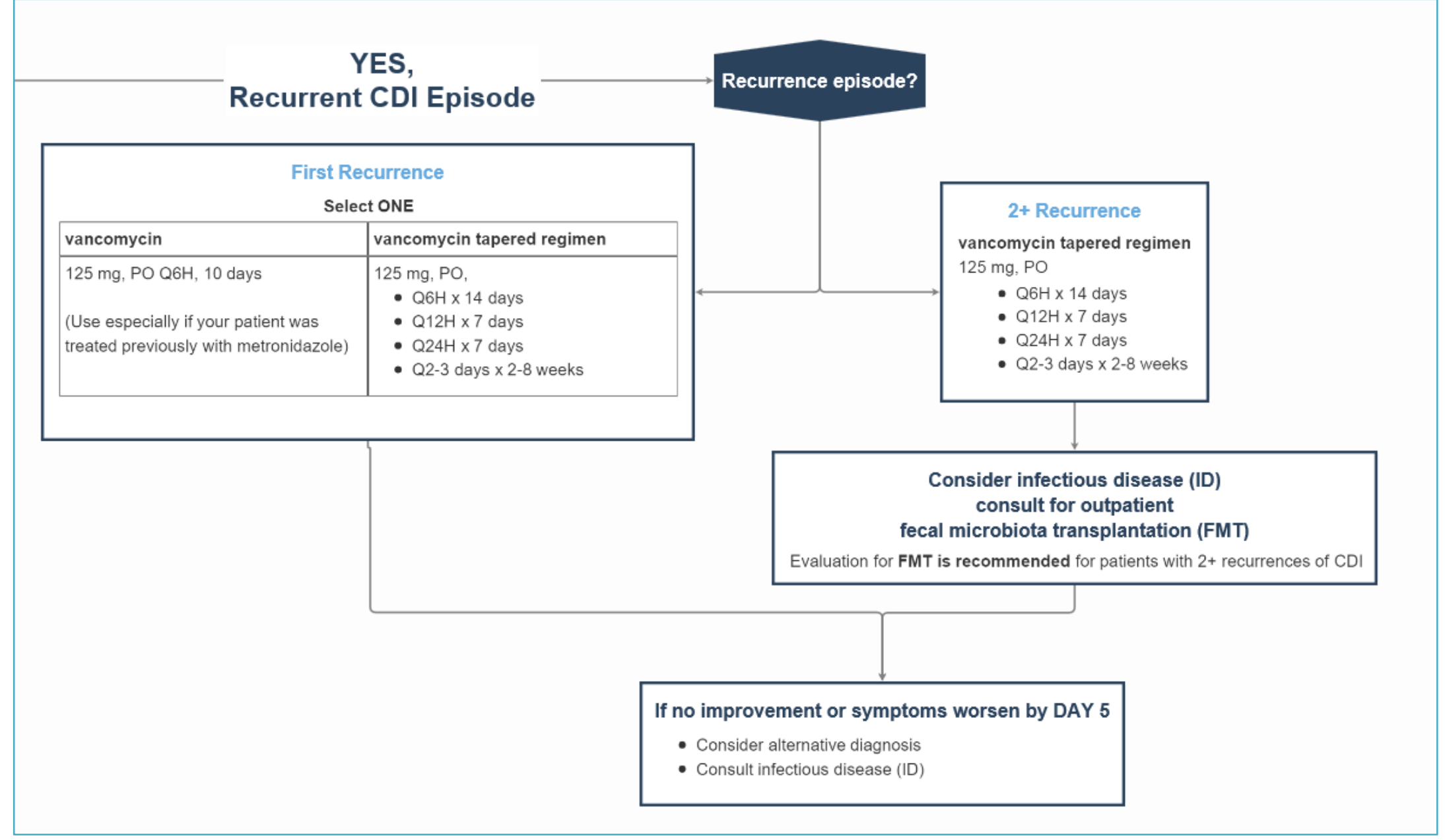




\section{Pathway Development Resource and Time Requirements}

\begin{tabular}{|c|c|}
\hline Role & Responsibilities \\
\hline Clinical Director & Convene panel and oversee clinical pathway development and deployment, and final report \\
\hline Pathways Program Manager & Manage pathway development and deployment, and draft final report \\
\hline EPC Director & Oversee project, review rapid review, draft report and final report \\
\hline Information Specialist & Conduct rapid review searches \\
\hline Physician Research Analyst & Assist in preparing rapid reviews, participate in pathway development, contribute to final report \\
\hline Research Analyst & Assist in preparing rapid reviews, contribute to final report \\
\hline Project Coordinator & Coordinate team meetings, assist with preparing deliverables \\
\hline Reference Database Manager & Prepare literature database for rapid reviews \\
\hline Administrative Assistant & Provide administrative assistance \\
\hline
\end{tabular}

Table 3. UPHS clinical pathway development process steps and direct time allocation for pathway development and dissemination

\begin{tabular}{|c|c|c|c|c|c|c|c|c|c|}
\hline $\begin{array}{c}\text { UPHS Clinical Pathway } \\
\text { Development and Dissemination } \\
\text { Framework }\end{array}$ & $\begin{array}{l}\text { Clinical } \\
\text { Director }\end{array}$ & $\begin{array}{l}\text { EPC } \\
\text { Director }\end{array}$ & $\begin{array}{l}\text { Pathways } \\
\text { Program } \\
\text { Manager }\end{array}$ & $\begin{array}{l}\text { Information } \\
\text { Specialist }\end{array}$ & $\begin{array}{l}\text { Physician } \\
\text { Research } \\
\text { Analyst }\end{array}$ & $\begin{array}{l}\text { Research } \\
\text { Analyst }\end{array}$ & $\begin{array}{l}\text { Reference } \\
\text { Database } \\
\text { Manager }\end{array}$ & $\begin{array}{l}\text { Project } \\
\text { Coordinator } \\
\text { and } \\
\text { Assistant }\end{array}$ & Total Hours \\
\hline 1. Identify clinical leader & 0 & 0 & 0 & 0 & 0 & 0 & 0 & 0 & 0 \\
\hline $\begin{array}{l}\text { 2. Recruit representative } \\
\text { stakeholders }\end{array}$ & 1 & 0 & 2 & 0 & 0 & 0 & 0 & 0 & 3 \\
\hline $\begin{array}{l}\text { 3. Conduct a rapid review of } \\
\text { existing guidelines and } \\
\text { pathways }\end{array}$ & 4 & 12 & 3 & 29 & 60 & 60 & 16 & 21 & 205 \\
\hline $\begin{array}{l}\text { 4. Develop pathway prototype for } \\
\text { stakeholder review at the initial } \\
\text { in-person meeting }\end{array}$ & 1 & 0 & 24 & 0 & 0 & 0 & 0 & 0 & 25 \\
\hline $\begin{array}{l}\text { 5. Review evidence and the } \\
\text { pathway prototype with key } \\
\text { stakeholders and elicit feedback }\end{array}$ & 3 & 1 & 3 & 0 & 1 & 0 & 0 & 0 & 8 \\
\hline $\begin{array}{l}\text { 6. Perform additional rapid } \\
\text { reviews as clinical questions } \\
\text { arise }\end{array}$ & 2 & 2 & 1 & 0 & 20 & 20 & 2 & 20 & 67 \\
\hline $\begin{array}{l}\text { 7. Update prototype and refine } \\
\text { asynchronously }\end{array}$ & 2 & 0 & 10 & 0 & 0 & 0 & 0 & 0 & 12 \\
\hline $\begin{array}{l}\text { 8. Quality assurance and finalizing } \\
\text { pathway content }\end{array}$ & 2 & 0 & 6 & 0 & 0 & 0 & 0 & 0 & 8 \\
\hline $\begin{array}{l}\text { 9. Develop messaging strategy } \\
\text { and disseminate for clinician } \\
\text { use }\end{array}$ & 1 & 0 & 1 & 0 & 0 & 0 & 0 & 0 & 2 \\
\hline 10. Monitoring and Maintenance & 0 & 0 & 1 & 0 & 0 & 0 & 0 & 0 & 1 \\
\hline Total Hours & 16 & 15 & 51 & 29 & 81 & 80 & 18 & 41 & 331 \\
\hline
\end{tabular}




\section{Discussion}

Clinical pathways are one method of integrating evidence into local health care settings and structures ${ }^{11,12}$ and the purpose of this ECRI Institute-Penn Medicine EPC project was to evaluate the feasibility of using an AHRQ EPC report as input into our standard pathway development and dissemination process, ${ }^{2}$ as well as examine how the report may have provided more value in this process, and the time and resource requirements. For this pilot project, we selected the Early Diagnosis, Prevention, and Treatment of Clostridium difficile: 2016 Update AHRQ EPC report, ${ }^{1}$ as C. difficile testing and treatment are areas with significant interest and activity in our health system.

\section{Utility and Applicability for Other Health Systems}

The results of this pilot project showed that AHRQ EPC reports could be a useful resource for health systems seeking to develop clinical pathways; however, these reports may be insufficient when used as the sole resource for developing clinical pathways. Penn Medicine uses a generalizable 10-step process for developing and disseminating clinical pathways, which can be adopted by other health systems. ${ }^{2}$ For all pathways projects, we recruit stakeholders from diverse functions, such as operations, quality, and informatics, in addition to those from related clinical domains, as representation by key stakeholders is essential for pathway development and adoption. This group is responsible for evaluating recent clinical practice guidelines and pathways, and having a common understanding of the evidence is an essential precursor to this step. ${ }^{5,13}$ For this pilot project, we used our process to develop an evidence-based clinical pathway for C. difficile treatment and found that that the 2016 AHRQ EPC report ${ }^{1}$ was most valuable in the early phase of this process, helping to establish a common understanding of the current evidence across our diverse stakeholder group. We reviewed the relevant information from the EPC report ${ }^{1}$ at the beginning of our initial in-person meeting. Since this report was viewed as coming from a trusted and neutral source, stakeholders placed high value on the evidence findings. We also found that this initial review of the report primed the group for further discussion when guideline recommendations differed from each other. In terms of usability, we found that information presented in a tabulated format or in forest plots was the most informative and conducive for review with stakeholders. We focused on Tables 6, 7, and Appendix Figures G16-G19 (forest plots) in the 2016 EPC report. We found that most stakeholders were able to quickly understand the data, which was critical given the short amount of time available with stakeholders. As our process relies on recent clinical practice guidelines and pathways to facilitate rapid development of pathway prototypes, we found that the lack of synthesis of guidelines and pathways in the EPC report ${ }^{1}$ limited the EPC report's utility.

For this pilot project the pathway development process was supported by multiple resources, including the CEP Director and PennPathways Program Manager (further discussed below), responsible for developing the initial pathway prototype and managing the review process, and an information specialist, research analyst, and physician research analyst, responsible for conducting the rapid evidence review. Total direct hours spent by the CEP Director and PennPathways Program Manager in developing the pathway and managing the process were 67 and total direct hours required for conducting the rapid review and synthesizing results were 272. Other health systems seeking to develop clinical pathways using a similar approach might find it challenging to support 272 hours — or almost seven 40-hour weeks — of rapid review development to synthesize existing guidelines and pathways. Having such 
information available and synthesized in an AHRQ EPC report would facilitate the utility of an EPC report in a local pathway development process.

Beyond examining the feasibility of this process, we also assessed utilization of our clinical pathway for $\mathrm{C}$. difficile treatment in the acute care setting by using our pathway platform analytics dashboard (Appendix D). As of August 31, the pathway has been viewed 325 times. View rates are comparable to our C. difficile testing pathway, which was launched on April 2, 2018. The promise of clinical pathways will likely be fully achieved only through tighter integration of pathways into the electronic health record. Future developments for this pathway include integration into the electronic health record to facilitate easier access to pathway support within provider workflow and potentially developing order sets to support adherence to the clinical pathway content. In our health system, integration of pathways will occur in phases. Phase one includes two interventions (Appendix J): (1) embedding hyperlinks to the CDI treatment pathway within the relevant medication ordering screens in the electronic health record and (2) providing access to the clinical pathway library from within the electronic health record. For this second intervention, clinicians will be able to browse and search for content without having to leave the electronic health record. Phase one changes went live on September 17, 2018.

A discussion of this pilot project would not be complete without commentary regarding our process and supporting infrastructure and considerations for adoption in other health care settings. Our process utilizes existing, recent clinical practice guidelines and pathways to facilitate rapid development of pathway prototypes. These products are advantageous as a starting point for pathway development for a number of reasons. First, guidelines are an evidence synthesis product and incorporate clinical judgment and provide recommendations, which are especially helpful in decisions where the supporting evidence is unclear. ${ }^{14}$ In addition, utilizing guidelines from major clinical societies and/or organizations may facilitate acceptance of the related pathway in a local setting due to their high level of credibility or influence. ${ }^{15}$ Lastly, creating pathway steps based on guideline recommendations greatly expedites the pathway prototyping process. For this project, we found a lack of summarized guidelines in the AHRQ EPC report, ${ }^{1}$ which prompted a rapid evidence review of recent guidelines and pathways by the ECRI Institute. The PennPathways Program Manager used these results to develop a prototype pathway with sufficient detail to guide clinical practice at the point of care. For settings that do not have the resources or capacity to conduct this type of rapid evidence review, in the absence of AHRQ EPC reports with summarized guidelines and pathways, it may be beneficial to identify a masters-prepared nurse interested in evidence-based practice and/or investigating partnerships with biomedical librarians to assist in conducting evidence searches (short-term) and training for capacity-building (long-term).

Having a centralized program manager role that oversees daily management and continued growth of the program is critical to its supporting infrastructure. ${ }^{2}$ In our setting, this role has reporting lines to the CEP Director and the UPHS chief quality officer. Specific responsibilities include providing direct support to pathway project teams through facilitating evidence review meetings, development of pathways using the PennPathways platform, messaging the availability of pathways to relevant stakeholders, working with stakeholders to integrate select pathways into computerized clinical decision support interventions, reporting on the utilization and clinical impact of pathways, and facilitating the updating of pathways as needed. This role is also responsible for growing the program by communicating the benefits of the approach and tools to internal stakeholders and the wider research community. This role often liaises with front-line clinicians and has the responsibility for impact evaluation; therefore, a clinical background as 
well as an advanced degree with experience in quantitative and translational research methods is important. We strongly recommend that this role directly report to quality and safety management (e.g., chief nursing officer and/or chief medical officer), since clinical pathways may have a considerable organizational or cultural impact. We recommend exploring the development of evidence-to-practice translation committees in settings that do not have the resources to support this role, as well as developing a senior nurse who has an interest in evidence-based practice and evidence translation.

Finally, we use a pathway development and dissemination platform to support our process. ${ }^{2}$ This platform was essential in our setting, given the geographic distribution of our care settings. This platform also provides the advantage of rendering clinical pathways in a format that is more conducive for viewing from within the electronic health record (a next step in our evidence-to-practice strategy). For health systems or settings with limited resources or for those that do not have this organizational complexity, utilizing technology tools commonly supported by organizations, such as Microsoft Visio for developing pathways and Microsoft SharePoint or a dedicated internal Web site for disseminating, may be sufficient in the early stages.

The Agency for Healthcare Quality and Research established the CDS Connect website to facilitate dissemination of CDS artifacts across health care systems and other settings. The CDI pathway was deposited on this website in October 2018. Other settings can download this content to further develop rules and logic to facilitate integration into an electronic health record or other technology. ${ }^{16}$

\section{Lessons Learned and Applicability for Other EPC Reports}

We utilized the UPHS standard, generalizable 10-step process for developing clinical pathways to facilitate the integration of evidence into clinical practice. ${ }^{2}$ We found that although the AHRQ EPC report ${ }^{1}$ was important in the early stages of this process, the lack of a synthesis of existing guidelines and pathways may act as a barrier to utilizing EPC reports to develop actionable tools for health systems. The UPHS process relies heavily on existing guidelines and pathways to develop clinical pathways with the level of detail required for providing decision support at the point of care. We recommend that AHRQ EPC reports include a summary and grading of current guidelines and pathways (using approaches similar to those we outline) to facilitate the use of EPC reports for this purpose. This additional content will be especially critical for health care settings that lack resources to conduct rapid evidence reviews of existing guidelines and pathways.

We noted a significant discrepancy between the 2016 EPC report ${ }^{1}$ and the most updated guideline at the start of our project (IDSA 2011). Specifically, the AHRQ report supported use of vancomycin as first-line treatment of non-severe CDI, while the IDSA guideline (2011) recommended metronidazole as the first-line treatment. Of these two sources, the AHRQ report ${ }^{1}$ incorporated more recent evidence. There was discussion during the stakeholder meeting with regard to whether the pathway should support the most recent evidence (use of vancomycin) as found in the AHRQ report, since doing so would seemingly conflict with the guideline recommendations. However, because a systematic review such as the AHRQ EPC report may not be considered equivalent from a legal, regulatory, or payer perspective to a national guideline, and because our experts were aware of the pending publication of an updated version of the IDSA C. difficile treatment guideline, we decided to contact IDSA to determine the expected date of release. Since the guideline was due to be released within days of our query, we decided to wait for the guideline release to finalize our pathway. The updated IDSA guideline 
was published (February 2018) during the final stages of pathway development, and supported the use of vancomycin as first-line therapy for non-severe CDI, which was consistent with the AHRQ EPC report. ${ }^{1}$ Thus, we did not have to make the challenging decision of creating local guidance that was consistent with the most updated evidence but inconsistent with national guideline recommendations. This situation illustrates that despite the unique value of AHRQ EPC reports, when kept up-to-date, these reports may not impact care unless national guidelines are also updated and are informed by AHRQ EPC reports or other systematic reviews of the latest evidence. Thus, we recommend AHRQ target relevant clinical societies in their EPC report dissemination strategy to ensure these important bodies are proactively informed of relevant EPC reports. In addition, to maximally impact clinical practice, the AHRQ EPC program should continue to grow partnerships with medical societies and other bodies that develop clinical practice guidelines, to ensure such guidelines are informed by the latest evidence available.

Other recommendations for the AHRQ EPC program include (1) facilitating the sharing of clinical pathways across health systems by providing a moderated platform to host evidencebased clinical pathways from health systems or other organization (or help facilitate the development of a consortium of academic medical centers to store and manage content) and (2) developing a methodology or tool for assessing the trustworthiness of clinical pathways.

\section{Conclusions}

The objective of this pilot project was to identify novel dissemination methods for AHRQ EPC reports. The ECRI Institute-Penn Medicine EPC opted to develop a clinical pathway, which can be an effective method for facilitating the integration of evidence into practice. ${ }^{11,12}$ We used the AHRQ EPC report ${ }^{1}$ findings as input to a standard process for developing and disseminating evidence-based clinical pathways. The AHRQ report ${ }^{1}$ offered value by providing a concise summary of the evidence, which was beneficial mainly because the evidence presented in the EPC report was current. We recommend that the AHRQ EPC program prioritize updating EPC reports by focusing on topics that address clinical and quality priorities of health systems.

We typically use clinical practice guidelines and existing pathways to develop our evidencebased clinical pathways. For this project, ECRI Institute conducted a rapid evidence review of guidelines and pathways as the AHRQ EPC report ${ }^{1}$ did not contain this information. Our pathway development process is a viable approach for other health systems; ${ }^{2}$ however, to facilitate this process, we recommend that the AHRQ EPC program include a synthesis of recent guidelines and pathways, as well as a grading of guideline quality, in their future reports to facilitate use of EPC reports in local pathway development processes. Our report included time and resource requirements to estimate the potential AHRQ EPC effort required for this recommendation. 


\section{References}

1. Butler M, Olson A, Drekonja D, et al. Early diagnosis, prevention, and treatment of clostridium difficile: update. (Prepared by the Minnesota Evidence-based Practice Center under Contract No. 290-2012-00016I.) AHRQ Publication No. 16-EHC012-EF. Rockville (MD): Agency for Healthcare Research and Quality (AHRQ); 2016 Mar. (Comparative effectiveness reviews; no.172).

http://www.effectivehealthcare.ahrq.gov/rep orts/final.cfm.

2. Flores EJ, Mull N, Lavenberg JG, Mitchell MD, Leas B, Williams A, Brennan PJ, Umscheid CA. Utilizing a ten-step framework to support the implementation of an evidence-based clinical pathways program [In Press]. BMJ Qual Saf. 2018.

3. Graham ID, Logan J, Harrison MB, et al. Lost in knowledge translation: time for a map? J Contin Educ Health Prof. 2006;26(1):13-24. http://dx.doi.org/10.1002/chp.47. PMID: 16557505.

4. Fervers B, Burgers JS, Voellinger R, et al. Guideline adaptation: an approach to enhance efficiency in guideline development and improve utilisation. BMJ Qual Saf. 2011 Mar;20(3):228-36. PMID: 21209134.

5. Powell BJ, Waltz TJ, Chinman MJ, et al. A refined compilation of implementation strategies: results from the Expert Recommendations for Implementing Change (ERIC) project. Implement Sci. 2015 Feb 12;10:21. http://dx.doi.org/10.1186/s13012-015-02091. PMID: 25889199.

6. Ransohoff DF, Pignone M, Sox HC. How to decide whether a clinical practice guideline is trustworthy. JAMA. 2013 Jan 09;309(2):139-40. http://dx.doi.org/10.1001/jama.2012.156703. PMID: 23299601.

7. Shekelle P, Eccles MP, Grimshaw JM, et al. When should clinical guidelines be updated?. BMJ. 2001 Jul 21;323:155-7.

8. Mitchell M, Leas B, Lavenberg J, et al. A simple guideline appraisal instrument based on IOM standards. BMJ Qual Saf. 2013;22(Suppl 1):A75.
9.

Shea BJ, Grimshaw JM, Wells GA, et al. Development of AMSTAR: a measurement tool to assess the methodological quality of systematic reviews. BMC Med Res Methodol. 2007;7:10. PMID: 17302989.

10. Proctor E, Silmere H, Raghavan R, et al. Outcomes for implementation research: conceptual distinctions, measurement challenges, and research agenda. Admin Policy Ment Health. 2011 Mar;38(2):65-76. http://dx.doi.org/10.1007/s10488-010-03197. PMID: 20957426.

11. Rotter T, Kinsman L, James E, et al. The effects of clinical pathways on professional practice, patient outcomes, length of stay, and hospital costs: Cochrane systematic review and meta-analysis. Eval Health Prof. 2012 Mar;35(1):3-27. http://dx.doi.org/10.1177/016327871140731 3. PMID: 21613244.

12. Kinsman L, Rotter T, James E, et al. What is a clinical pathway? Development of a definition to inform the debate. BMC Med. 2010 May 27;8:31. PMID: 20507550.

13. Grol R. Successes and failures in the implementation of evidence-based guidelines for clinical practice. Med Care. 2001 Aug;39(8 Suppl 2):II46-54. PMID: 11583121.

14. Woolf S, Schunemann HJ, Eccles MP, et al. Developing clinical practice guidelines: types of evidence and outcomes; values and economics, synthesis, grading, and presentation and deriving recommendations. Implement Sci. 2012;7:61. PMID: 22762158.

15. Kastner M, Bhattacharyya O, Hayden L, et al. Guideline uptake is influenced by six implementability domains for creating and communicating guidelines: a realist review. J Clin Epidemiol. 2015 May;68(5):498-509. http://dx.doi.org/10.1016/j.jclinepi.2014.12. 013. PMID: 25684154.

16. CDS Connect. [Web site]. Rockville (MD): Agency for Healthcare Research and Quality (AHRQ). https://cds.ahrq.gov/. Accessed October 03, 2018. 


\section{Abbreviations and Acronyms}

$\begin{array}{ll}\text { AHRQ } & \text { Agency for Healthcare Research and Quality } \\ \text { AMSTAR } & \text { A MeaSurement Tool to Assess systematic Reviews } \\ \text { CDI } & \text { Clostridium difficile Infection } \\ \text { CEP } & \text { Center for Evidence-base Practice } \\ \text { EPC } & \text { Evidence-based Practice Center } \\ \text { UPHS } & \text { University of Pennsylvania Health System }\end{array}$




\section{Appendix A. University of Pennsylvania Health System Guidelines, Pathways, and Algorithms Standard Medline Search Methods}

0_filter_pathways-algorithm: Stock pathways search

1. exp Critical Pathways/

2. ((clinical or critical or care) adj path\$).mp.

3. (care adj (map\$ or plan\$)).mp.

4. patient care planning/

5. algorithm\$.mp. or exp Algorithms/

6. or $/ 1-5$

7. nursing protocol\$.mp.

8. (nursing adj (care plan or protocol\$)).mp.

9. professional standard\$.mp.

10. or/7-9

11. 6 or 10

0_guideline: Basic search terms for guidelines

1. (guideline* or guidance).mp. or exp Guideline/ or exp Practice Guideline/ 


\section{Appendix B. PennPathways Online Library (subset) and Example Pathway}

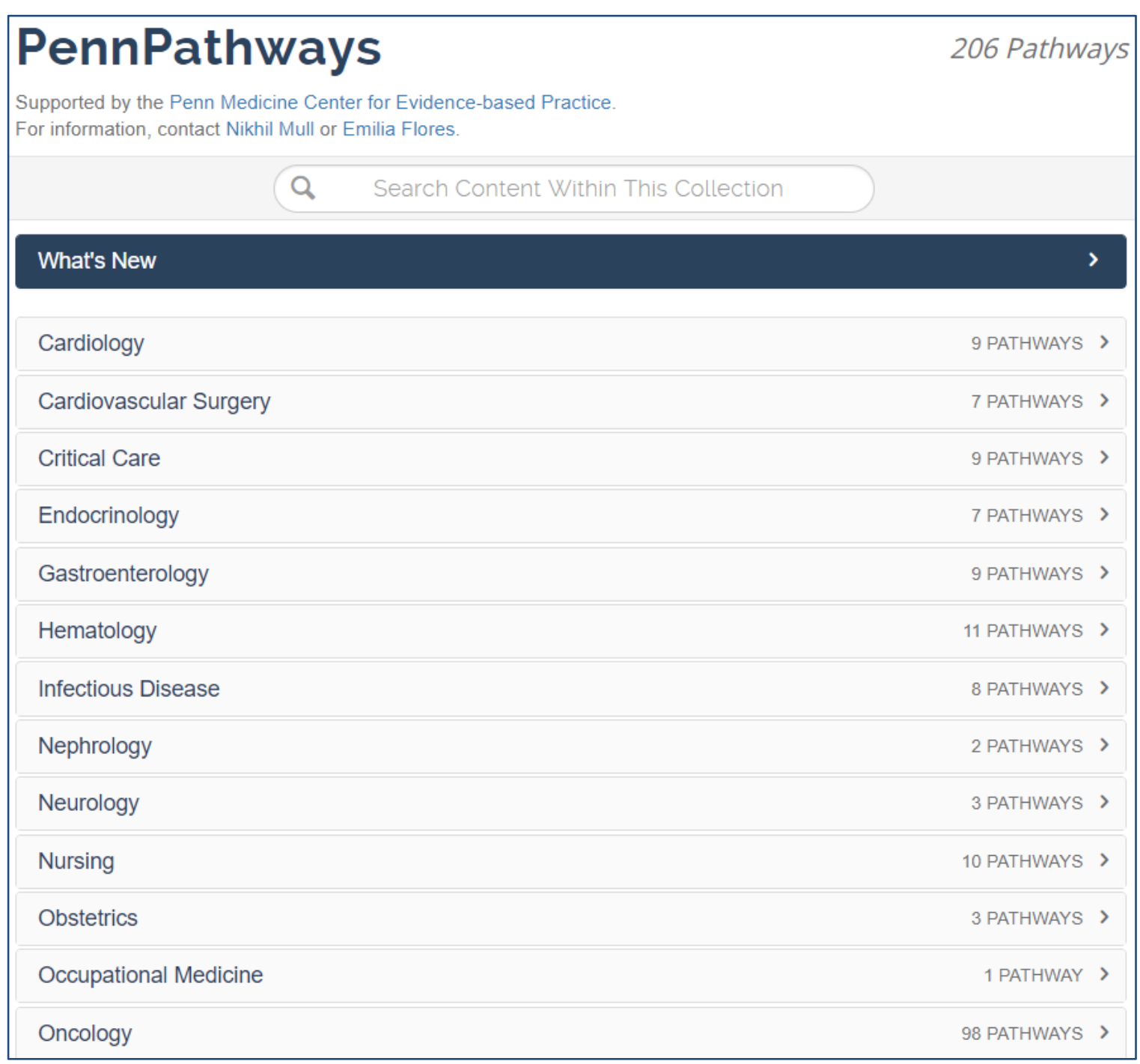




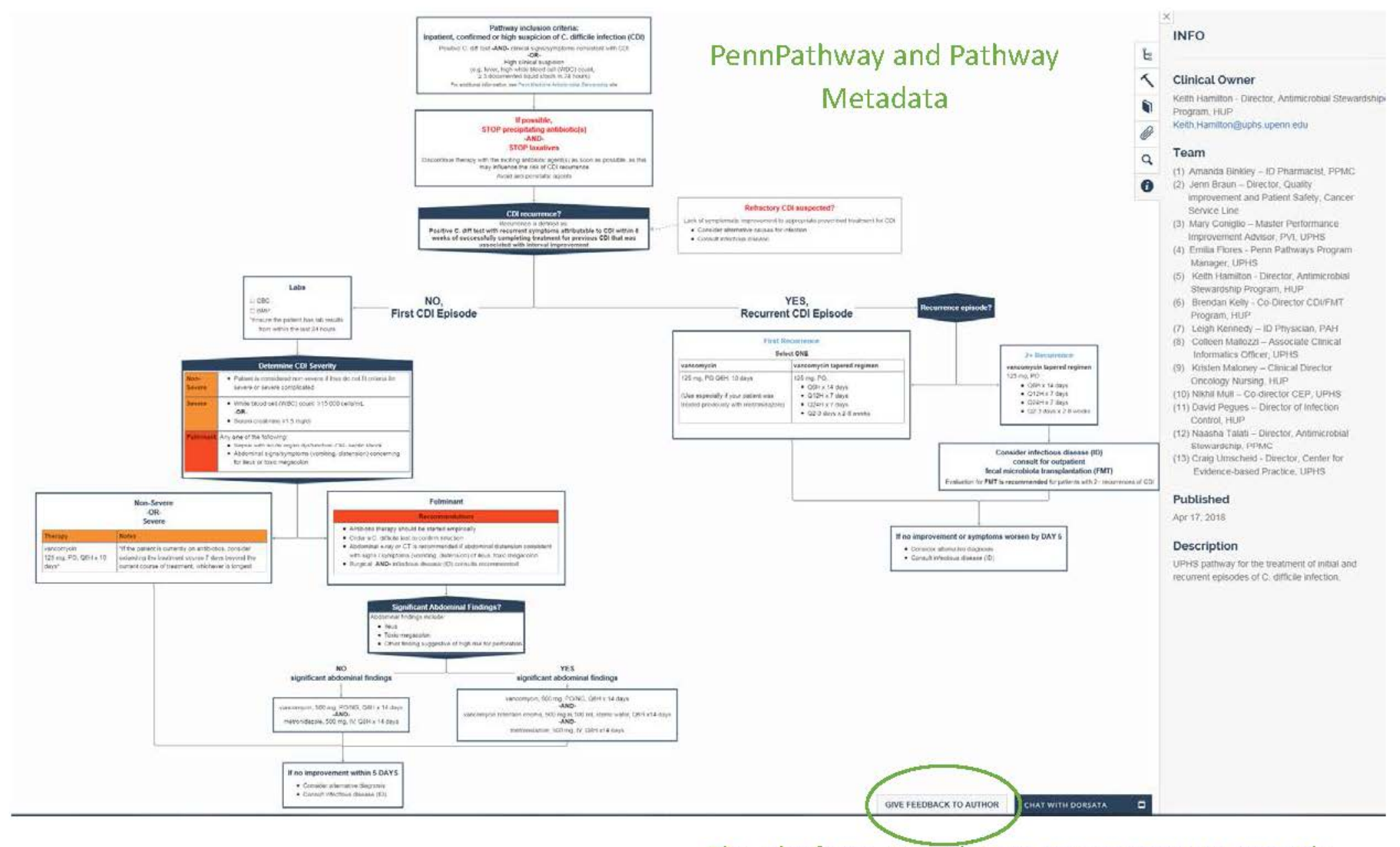

The platform provides an easy means to provide feedback to the pathway owner 


\title{
Appendix C. PennPathways Mobile Application
}

\author{
UPHS users can download \\ the mobile app
}

Users can search using pathway keywords or scroll through the list

Users can view pathway content and click through decision points to obtain decision support
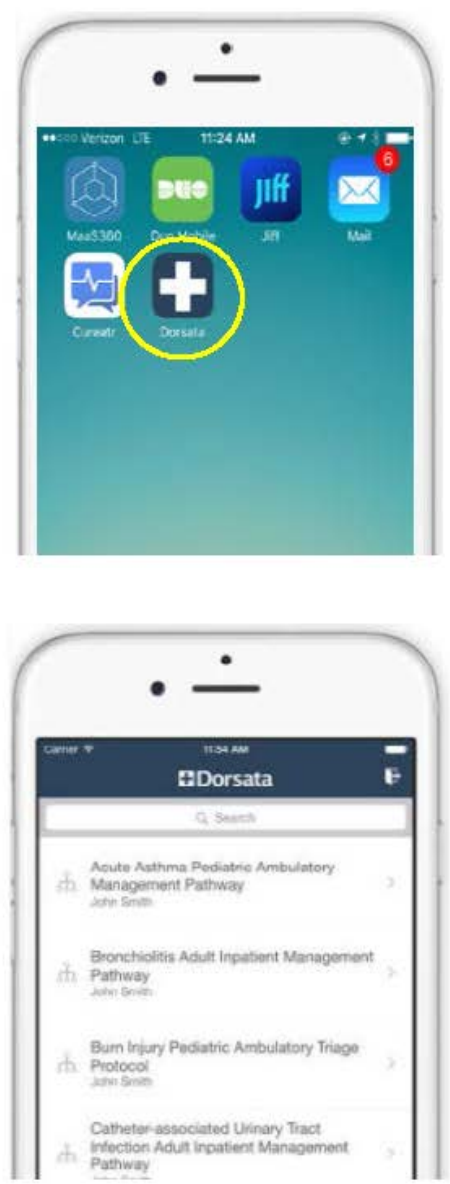

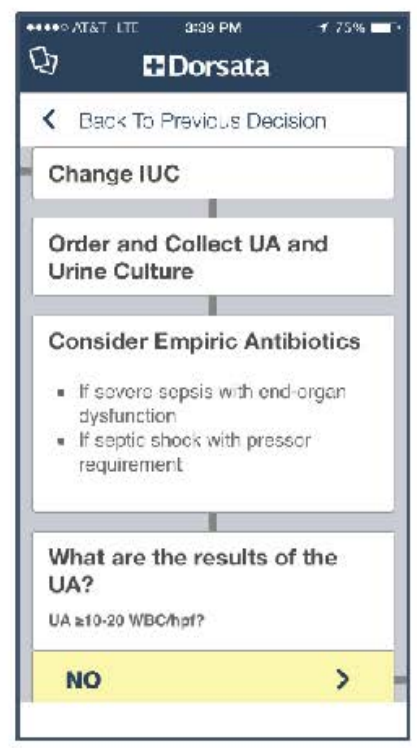




\section{Appendix D. PennPathways Analytics Dashboard}

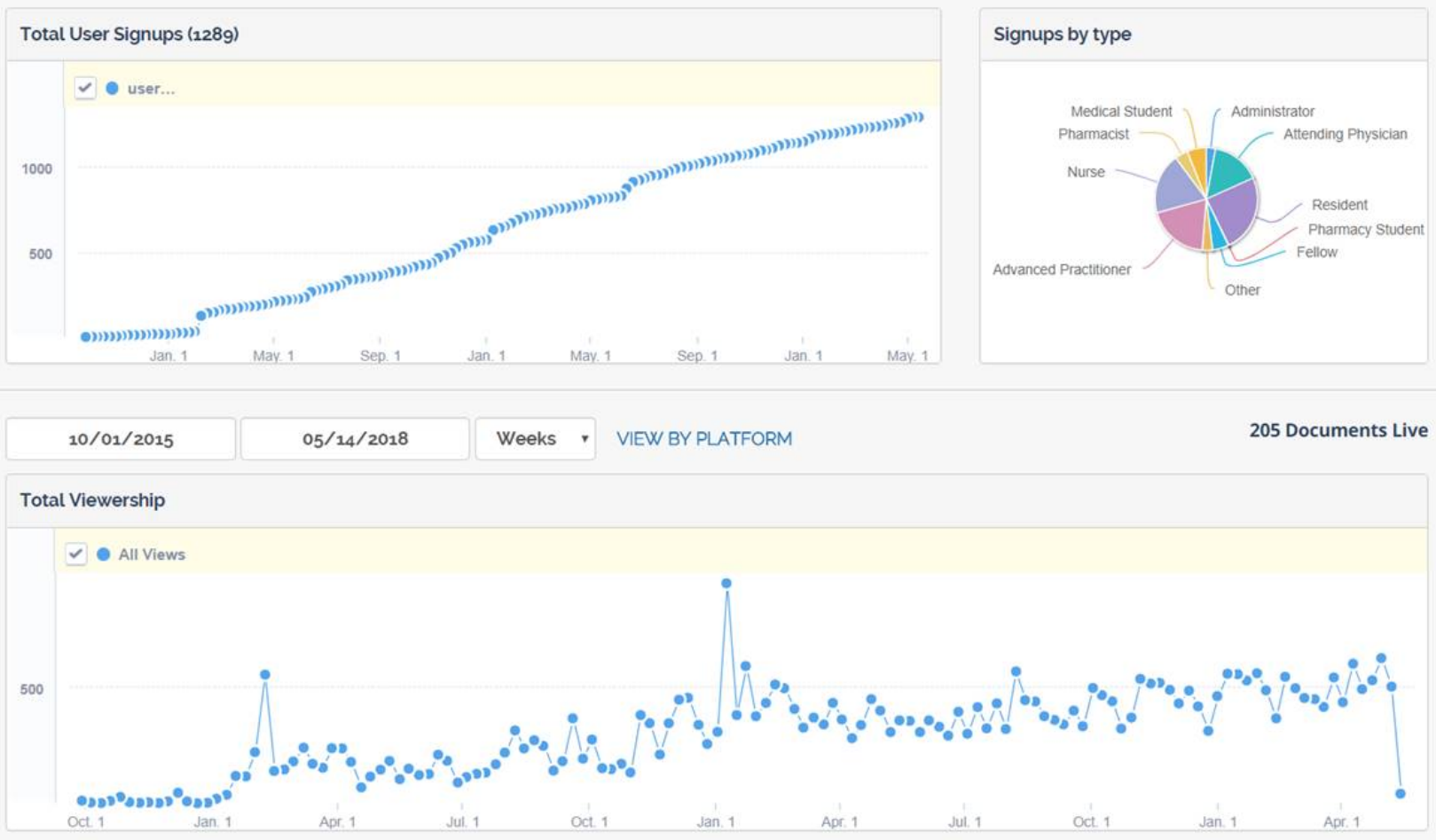

Screenshot date: May 2018 


\section{Appendix E. CEP Trustworthy Guideline Appraisal Tool}

\section{CEP Trustworthy Guideline Appraisal Tool}

Development version: February 2014

The purpose of this instrument is to focus on the aspects of a guideline that may reduce the trust a clinical user can have in the guideline and distinguish weaknesses in documentation (e.g., guideline does not have a documented updating process) from weaknesses in the guidance itself (e.g., recommendations are outdated). It is based on the eight domains included in the Institute of Medicine’s publication: Clinical Practice Guidelines We Can Trust (1).

Current appraisal instruments like AGREE (2) and the G-I-N standards (3) emphasize documentation. They are important standards for guideline developers but may be harder for clinicians and other persons who are not methodology experts to apply, and their length may discourage their use outside of formal systematic reviews and health care technology assessment (HTA) reports. This new instrument is designed to be brief, and easy and consistent to apply.

\section{Transparency}

\begin{tabular}{|l|l|}
\hline $\begin{array}{l}\text { Guideline } \\
\text { Rating }\end{array}$ & Definition \\
\hline A & Guideline development methods are fully disclosed. \\
\hline B & Guideline development methods are partially disclosed. \\
\hline C & Guideline development methods are not disclosed. \\
\hline
\end{tabular}

The grader must refer to any cited methods supplements or other supporting material when evaluating the guideline. Methods should include:

- Who wrote the initial draft

- How the committee voted on or otherwise approved recommendations

Evidence review, external review and methods used for updating are not addressed in this standard.

\section{Conflict of interest}

\begin{tabular}{|l|l|}
\hline $\begin{array}{l}\text { Guideline } \\
\text { Rating }\end{array}$ & Definition \\
\hline A & $\begin{array}{l}\text { Funding of the guideline project is disclosed, disclosures are made for } \\
\text { each individual author, and there are no potential financial or other } \\
\text { conflicts in the guideline project funding or among the lead authors. }\end{array}$ \\
\hline B & $\begin{array}{l}\text { Guideline states that the lead authors have no potential financial or other } \\
\text { conflicts, } \\
\text { but does not disclose the funding source for the guideline project. }\end{array}$ \\
\hline C & $\begin{array}{l}\text { One or more lead authors, or the guideline project as a whole, is funded } \\
\text { by a sponsor with potential financial or other conflicts of interest. }\end{array}$ \\
\hline NR & $\begin{array}{l}\text { Guideline does not report on potential conflicts of individual authors or the } \\
\text { funding of the guideline. }\end{array}$ \\
\hline
\end{tabular}


For purposes of this checklist, conflicts of interest include employment by, consulting for, or holding stock in companies doing business in fields affected by the guideline, as well as related financial conflicts. This definition should not be considered exclusive.

As much as anything, this is a surrogate marker for thorough reporting, since it may be assumed that guideline projects are funded by the sponsoring organization and many authors think it unnecessary to report a non-conflict.

\section{Guideline development group}

\begin{tabular}{|l|l|}
\hline $\begin{array}{l}\text { Guideline } \\
\text { Rating }\end{array}$ & Definition \\
\hline A & $\begin{array}{l}\text { Guideline development group includes 1) methodological experts, 2) } \\
\text { representatives of multiple specialties, and 3) representatives of patients } \\
\text { or the general public. }\end{array}$ \\
\hline B & $\begin{array}{l}\text { Guideline development group includes representatives of two of the } \\
\text { above numbered categories, but not all three. }\end{array}$ \\
\hline C & Guideline development group includes only one or none of the above. \\
\hline NR & Affiliations of guideline developers not reported. \\
\hline
\end{tabular}

The purpose of this standard is to ensure that supporters of competing procedures, clinicians with no vested interest in utilization of one procedure or another, methodologists, and patients or potential patients are involved in development of the guideline. Involvement of methodologists or HTA specialists in the systematic review represents sufficient involvement in the guideline development group for our purposes. In the absence of any description of the guideline group, assume the named authors of the guideline and any corresponding systematic reviews are the guideline group.

\section{Systematic review}

\begin{tabular}{|l|l|}
\hline $\begin{array}{l}\text { Guideline } \\
\text { Rating }\end{array}$ & Definition \\
\hline A & Guideline is based on a systematic review of the evidence. \\
\hline B & $\begin{array}{l}\text { Guideline is based on a review which does not meet systematic review } \\
\text { criteria, } \\
\text { or cannot be readily obtained. }\end{array}$ \\
\hline C & Guideline is not based on a review of the evidence. \\
\hline
\end{tabular}

In order to qualify as a systematic review, the review must do all of the following:

- Describe itself as systematic or report search strategies using multiple databases

- Define the scope of the review (including key questions and the applicable population)

- Either include quantitative or qualitative synthesis of the data or explain why it is not indicated

Note: the review can be incorporated into the guideline document or published separately and referenced in the guideline document. The review does not need to be performed by the same group that develops the guideline. 
Note: this element does not address the quality of the systematic review: simply whether it exists. Concerns about quality or bias of the review will be discussed in text, where the analyst will explain whether the weaknesses of the review weaken the validity or reliability of the guideline.

Note: a guideline may be rated $\mathrm{B}$ on this domain even if the review on which it is based is not available to us. This potential weakness of the guideline should be discussed in the report.

\section{Citing and grading the supporting evidence}

\begin{tabular}{|l|l|}
\hline $\begin{array}{l}\text { Guideline } \\
\text { Rating }\end{array}$ & Definition \\
\hline A & $\begin{array}{l}\text { Specific supporting evidence (or lack thereof) for each recommendation is } \\
\text { cited and graded. }\end{array}$ \\
\hline B & $\begin{array}{l}\text { Specific supporting evidence (or lack thereof) for each recommendation is } \\
\text { cited but the evidence is not graded. }\end{array}$ \\
\hline C & Recommendations are not supported by specific evidence. \\
\hline
\end{tabular}

To score a B on this domain, recommendations should include specific citations to the relevant evidence, specific references to evidence tables or written evidence summaries that include citations, or an indication that no evidence was available. The use of any standardized system to grade the evidence supporting a recommendation is acceptable for purposes of supporting an A rating.

\section{Recommendations}

\begin{tabular}{|l|l|}
\hline $\begin{array}{l}\text { Guideline } \\
\text { Rating }\end{array}$ & Definition \\
\hline A & $\begin{array}{l}\text { 1) Considerations for each recommendation (i.e., benefits and harms of a } \\
\text { particular action) are documented and a strength of recommendation is } \\
\text { provided; and 2) recommendations are presented in an actionable form. }\end{array}$ \\
\hline B & Either one or the other of the above numbered criteria is met. \\
\hline C & Neither of the above criteria are met. \\
\hline
\end{tabular}

The use of any standardized system to grade the strength of a recommendation is acceptable for purposes of this appraisal. In order to be actionable, the guideline recommendation should specify the population to which the recommendation applies, the intervention in question, and the circumstances under which it should be carried out (or not carried out). The language used in the recommendations should also be consistent with the strength of the recommendation (e.g., directive and active language like "should" or "should not" for strong recommendations, and passive language like "consider" for weak recommendations). A figure or algorithm is considered actionable as long as it is complete enough to incorporate all the applicable patients and interventions. Please see the NICE manual (4) for a helpful discussion of actionability in guidelines. 


\section{External review}

\begin{tabular}{|l|l|}
\hline $\begin{array}{l}\text { Guideline } \\
\text { Rating }\end{array}$ & Definition \\
\hline A & $\begin{array}{l}\text { Guideline was made available to external groups and/or the public for } \\
\text { review. }\end{array}$ \\
\hline B & $\begin{array}{l}\text { Guideline was reviewed by officers or members of the sponsoring body } \\
\text { only. }\end{array}$ \\
\hline C & $\begin{array}{l}\text { Guideline was not reviewed by anyone outside of the authoring } \\
\text { committee. }\end{array}$ \\
\hline NR & No external review process is described. \\
\hline
\end{tabular}

The purpose of this domain is to report whether or not there was consultation with persons or groups who might have a different perspective than members of the organization developing the guideline. If the guideline was reviewed and/or voted on by the board of the sponsoring body only, that is not an outside review, and this domain would be marked "B." NR is likely to be common for this domain.

\section{Updating and currency of guideline}

\begin{tabular}{|l|l|}
\hline $\begin{array}{l}\text { Guideline } \\
\text { Rating }\end{array}$ & Definition \\
\hline A & Guideline is current and an expiration date or update process is specified. \\
\hline B & Guideline is current but no expiration date or update process is specified. \\
\hline C & Guideline is outdated. \\
\hline
\end{tabular}

A guideline is considered current if it is within the developers' stated validity period, or if no period or expiration data is stated, the guideline was published in the past three years (NOTE: the specific period may be changed at the discretion of the analyst reviewing the guideline, based on whether the technology is mature and whether there is a significant amount of recent evidence). A guideline must address new evidence when it is updated. A guideline which is simply reendorsed by the panel without searching for new evidence must be considered "outdated."

\section{Reporting the results of this appraisal}

We do not attempt to convert the results of this appraisal into a numeric score. Instead we present a table listing the guidelines and how they are rated on each standard. Colored cells in the table reinforce the grades in the table, though use of color is optional. This facilitates qualitative understanding by the reader, who can see for what areas the available guidelines as a group are weak or strong as well as which guidelines are weaker or stronger. 
Sample guideline appraisal table

\begin{tabular}{|l|c|c|c|c|}
\hline Domain & Guideline A & Guideline B & Guideline C & Guideline D \\
\hline 1. Transparency & A & B & B & C \\
\hline 2. Conflict of interest & A & B & NR & C \\
\hline 3. Development group & C & C & C & C \\
\hline 4. Systematic review & A & A & B & B \\
\hline 5. Grading of evidence & B & NR & NR & B \\
\hline 6. Recommendations & A & B & A & B \\
\hline 7. External review & B & NR & NR & C \\
\hline 8. Updating & A & B & B & C \\
\hline
\end{tabular}

\section{Reporting the level of evidence}

The purpose of the Trustworthy Guideline appraisal is to assess the methodologic reliability of the guideline and its development, and not to assess the level or quality of evidence for specific guideline recommendations. This is because guidelines usually include multiple recommendations, some of which may be supported by better evidence than others.

The suggested place for reporting level of evidence is in the table of recommendations, beside or immediately below each recommendation from each guideline developer. That way the reader can easily determine which recommendations are supported by reliable evidence and which have to be based on expert opinion. Numerous scales are already available, such as the one from the GRADE Working Group (5).

\section{References}

1. Institute of Medicine (U.S.). Committee on Standards for Developing Trustworthy Clinical Practice Guidelines. Clinical practice guidelines we can trust. Graham R, Mancher M, Wolman DM, Greenfield S, Steinberg E, editors. Washington, DC: National Academies Press; 2011. http://www.iom.edu/Reports/2011/Clinical-Practice-Guidelines-We-Can-Trust.aspx

2. Brouwers MC, Kho ME, Browman GP, Burgers JS, Cluzeau F, Feder G, et al. AGREE II: Advancing guideline development, reporting and evaluation in health care. J Clin Epidemiol. 2010 Dec; 63(12):1308-11.

3. Qaseem A, Forland F, Macbeth F, Ollenschlager G, Phillips S, van der Wees P, et al. Guidelines International Network: toward international standards for clinical practice guidelines. Ann Intern Med. 2012 Apr 3;156(7):525-31.

4. National Institute for Health and Clinical Excellence. The guidelines manual. London: National Institute for Health and Clinical Excellence; November 2012. http://publications.nice.org.uk/the-guidelines-manual-pmg6

5. Guyatt GH, Oxman AD, Kunz R, Falck-Ytter Y, Vist GE, Liberati A, et al. GRADE: Going from evidence to recommendations. BMJ. 2008;336(7652):1049-51. 


\section{Appendix F. Modified AMSTAR Scale}

\section{Modified AMSTAR scale for appraisal of systematic reviews}

This scale was adapted from the original AMSTAR instrument by the University of Pennsylvania Health System Center for Evidence-based Practice. it was modified to enable more efficient, objective, and reproducible assessments that can be incorporated into rapid systematic reviews. The items are designed to be answered as "Yes" or "No". The scale does not require calculation of a numeric score, but can be used to visually map the characteristics of systematic reviews, as demonstrated in the sample table.

\section{Literature search:}

1. Search terms described?

2. Databases searched described and two or more databases searched?

Study selection:

3. Inclusion/exclusion criteria described?

4. Number of included/excluded studies along with reasons of exclusion described?

5. Studies screened by two independent reviewers for inclusion?

Data synthesis and evaluation of evidence base:

6. Data extracted by two independent reviewers?

7. Individual study quality assessed?

8. Heterogeneity between study results assessed qualitatively and/or quantitatively?

9. Publication bias assessed qualitatively and/or quantitatively?

10. Characteristics of included studies reported in evidence table?

11. Funding source(s) disclosed and no obvious conflict of interest?

Reference: Shea BJ, Grimshaw JM, Wells GA, Boers M, Andersson N, Hamel C, et al. Development of AMSTAR: a measurement tool to assess the methodological quality of systematic reviews. BMC Medical Research Methodology. 2007;7:10.

\section{Sample systematic review appraisal table}

\begin{tabular}{|l|c|c|c|}
\hline Domain & Review A & Review B & Review C \\
\hline 1. Search terms & $\mathrm{Y}$ & $\mathrm{Y}$ & $\mathrm{N}$ \\
\hline 2. Databases & $\mathrm{Y}$ & $\mathrm{Y}$ & $\mathrm{NR}$ \\
\hline 3. Inclusion criteria & $\mathrm{N}$ & $\mathrm{N}$ & $\mathrm{Y}$ \\
\hline 4. Included/excluded studies & $\mathrm{Y}$ & $\mathrm{Y}$ & $\mathrm{Y}$ \\
\hline 5. Independent screening & $\mathrm{N}$ & $\mathrm{Y}$ & $\mathrm{N}$ \\
\hline 6. Independent data extraction & $\mathrm{Y}$ & $\mathrm{N}$ & $\mathrm{NR}$ \\
\hline 7. Study quality & $\mathrm{N}$ & $\mathrm{Y}$ & $\mathrm{Y}$ \\
\hline 8. Heterogeneity & $\mathrm{Y}$ & $\mathrm{NR}$ & $\mathrm{Y}$ \\
\hline 9. Publication bias & $\mathrm{N}$ & $\mathrm{NR}$ & $\mathrm{N}$ \\
\hline 10. Evidence tables & $\mathrm{N}$ & $\mathrm{Y}$ & $\mathrm{Y}$ \\
\hline 11. Funding source & $\mathrm{Y}$ & $\mathrm{N}$ & $\mathrm{NR}$ \\
\hline
\end{tabular}

\section{Center for} Evidence-based Practice 琴 Penn Medicine e) Copyright 2016 by the Trustees of the University of Pennsylvania. All rights reserved. No part of this publication may be reproduced without permisgion in writing from the Trustees of the University of Pennsylvania. 


\section{Appendix G. IDSA 2018 Clinical Practice Guideline Recommendation Differences as Noted in the Pathway}

[1] The IDSA doesn't provide a definition for CDI recurrence: Do we want to keep the ACG definition of "CDI within 8 weeks of completion of therapy", remove, or modify?

[2] IDSA definitions for SEVERE CDI:

(2.1) IDSA now recommends avalues for serum creatinine levels (i.e. $<1.5 \mathrm{mg} / \mathrm{dL}$ ) -- Should we use this definition or continue to use the guidance of 1.5 times the baseline?

(2.2) IDSA guidelines do not include age in the definition -- Should we continue to include this in our definition?

[5] Fulminant CDI: The IDSA recommends that "Antibiotic therapy should be started empirically if a substantial delay in laboratory confirmation is expected (eg, >48 hours) OR IF PATIENT PRESENTS WITH FULMINANT CDI. For other patients, antibiotic therapy should be started after diagnosis to limit overuse of antibiotics and associated toxicities including overgrowth of multidrug-resistant pathogens"

- Should we recommend empiric treatment for fulminant, with the condition that a CDI test be submitted?

[6] Vancomycin, fidaxomycin, and metronidazole: IDSA guidelines recommend vancomycin or fidaxomycin (use of fidaxomycin may be associated with a lower likelihood for recurrence) and recommend starting with 10 days and then extending to 14 if symptoms haven't resolved

(6.1) Should we include fidaxomycin?

(6.2) Duration: should we adopt these recommendations

(6.3) For non-severe: metronidazole is recommended in cases where access to vancomycin/fidaxomycin is limited: Should we remove metronidazole? If we do this, we could collapse the non-severe and severe categories...

[7] Treatment Contraindications: No guidance provided in the IDSA guidelines -- remove table to avoid confusion?

[8] Imaging: The IDSA doesn't provide guidance on imaging. Should we recommend imaging? If so, please provide responses to the following questions regarding imaging types A and B below:

(A) Abdominal CT with PO/IV contrast (or does the team recommend non-contrast?)

(B) Abdominal x-ray with patient in an upright position

(8.1) Should one or both be recommended?

(8.2) Are there other studies that you'd recommend in addition or in place of A and B?

[9] Follow up during initiate episode treatment: The IDSA does not provide guidance -- Should we keep our recommendation of 5 days?

[10] IDSA recommends vancomycin $125 \mathrm{mg}$, Q6, 10 days if metronidazole was used for the initial treatment. If we opt to include metronidazole as a recommendation for an initial episode of non-severe CDI, then should we include this IDSA recommendation?

[11] Recurrent CDI: Treatments have been updated to reflect IDSA recommendations: please review and provide feedback, if any. 


\section{Appendix H. Final CDI Clinical Pathway}

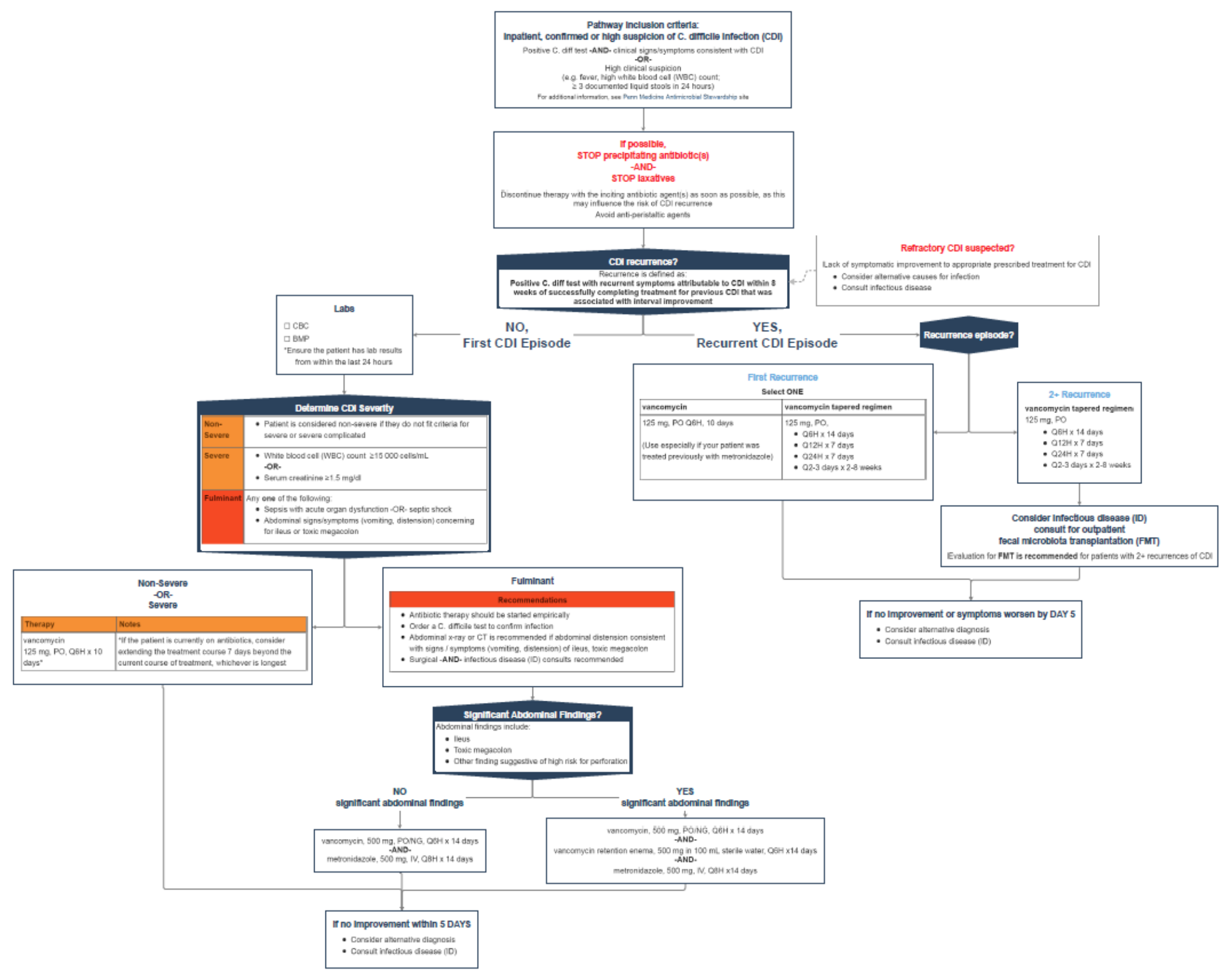




\section{Appendix I. Screen Savers Used for Messaging the C. difficile Treatment Pathway}

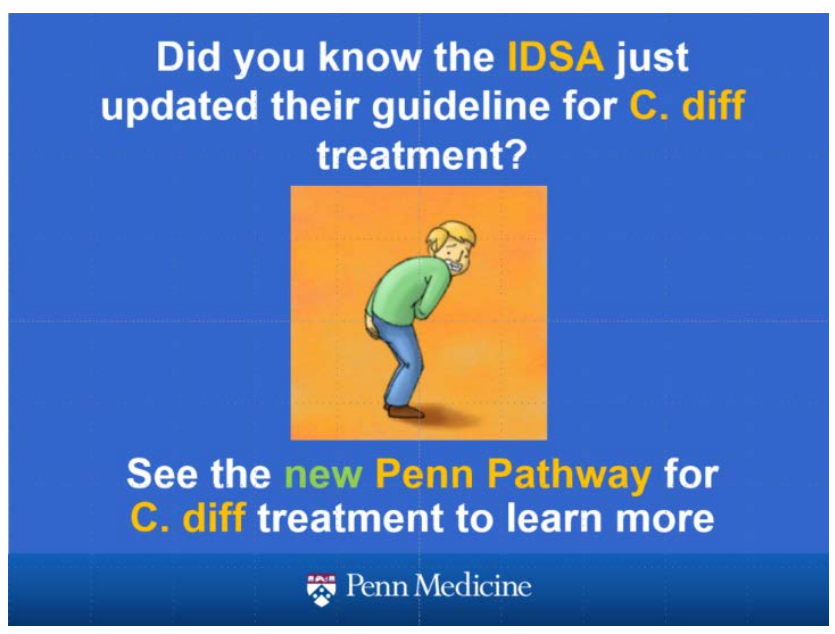

\section{There's a new way to treat C. diff!}

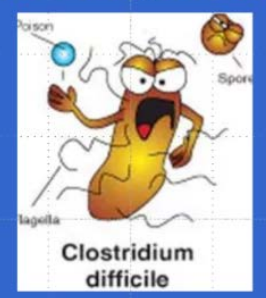

See the new C. diff treatment pathway for the most recent IDSA recommendations

Penn Medicine 


\section{Appendix J. Clinical Pathway Integration into the Electronic Health Record (Phase One)}

Example 1: The oral vancomycin ordering screen in the electronic health record includes a link to the Clostridium difficile treatment pathway. Ordering providers can click on this link to review the algorithm for evidence-based CDI treatment.

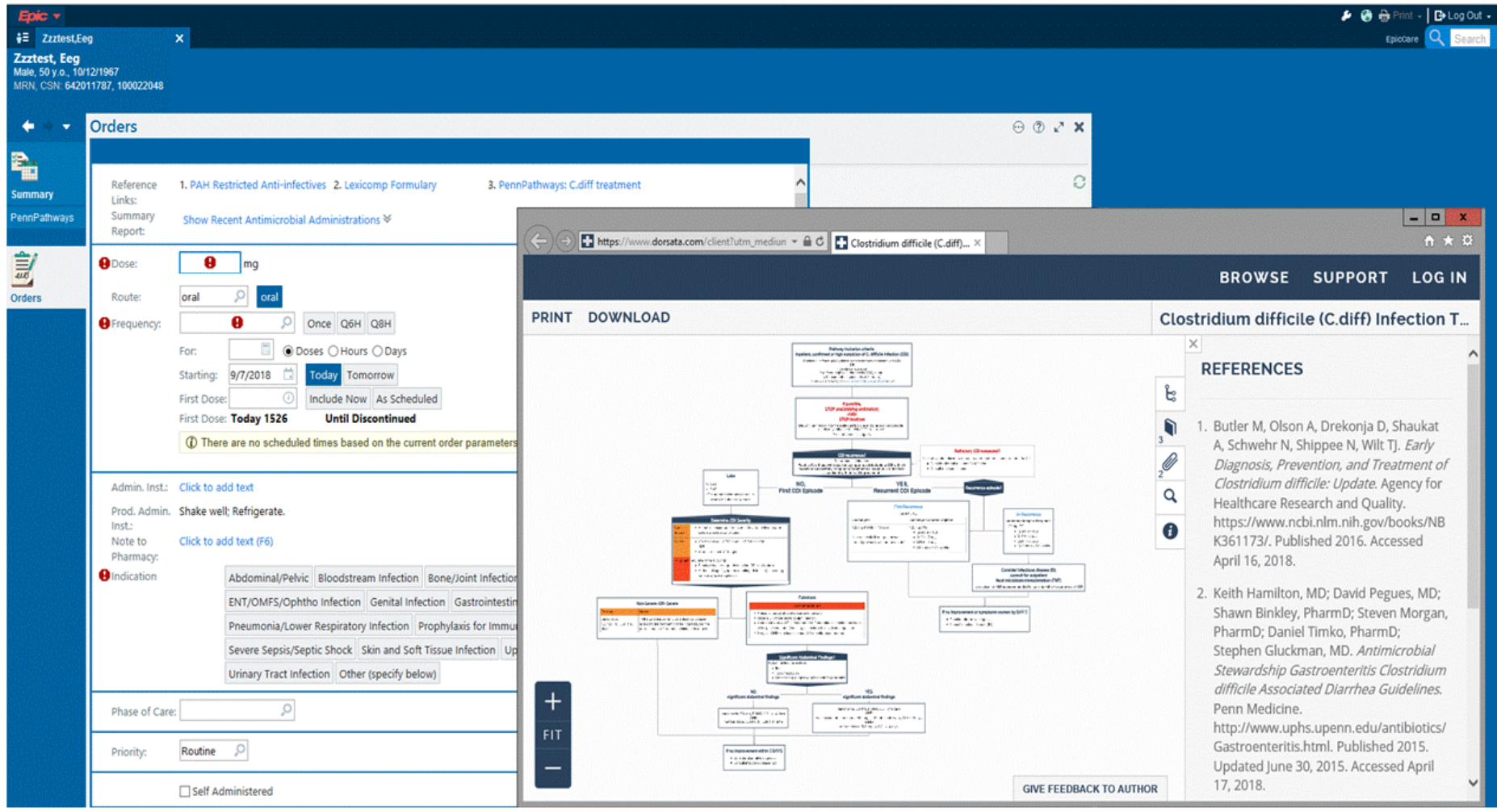

(C) 2018 Epic Systems Corporation. Used with permission.

Example 2: Clinicians are able to view the clinical pathways library from within the electronic health record. Clinicians can search or browse the library and can click on a pathway to review the details.

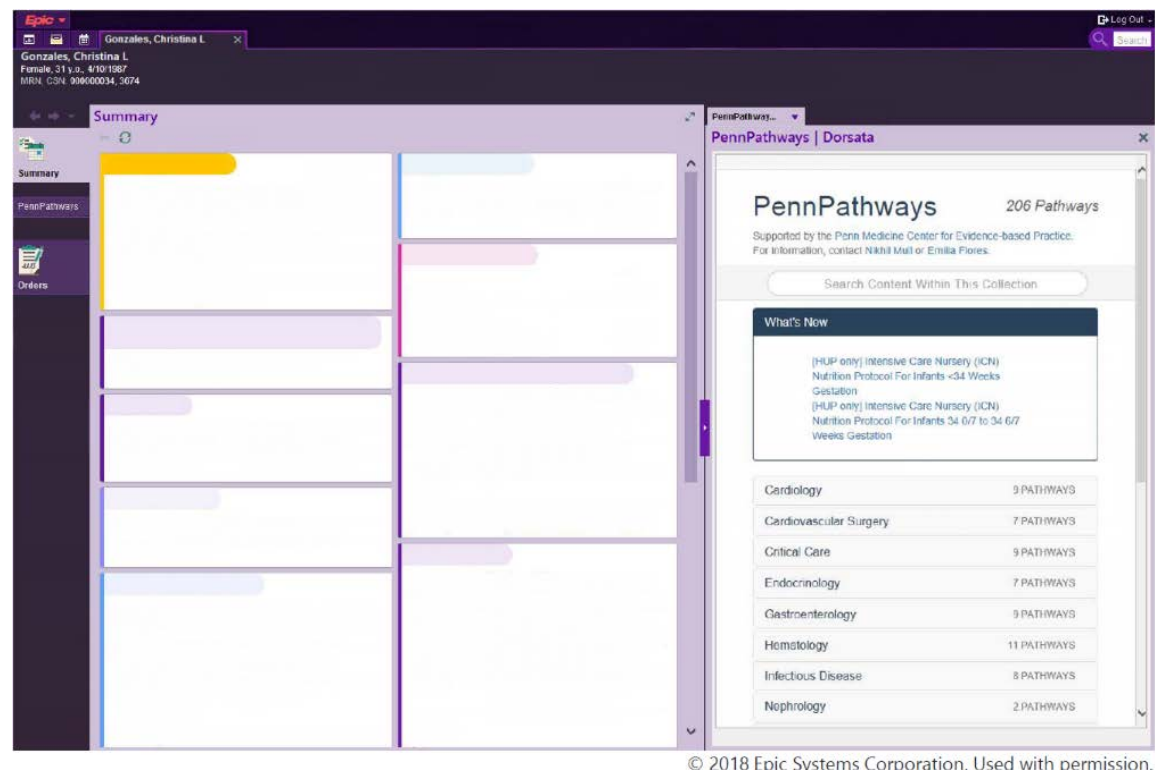


In this example, the Clostridium difficile treatment pathway is displayed. Clinicians can click on the decision points (displayed in yellow) to traverse the pathway and understand treatment guidance.
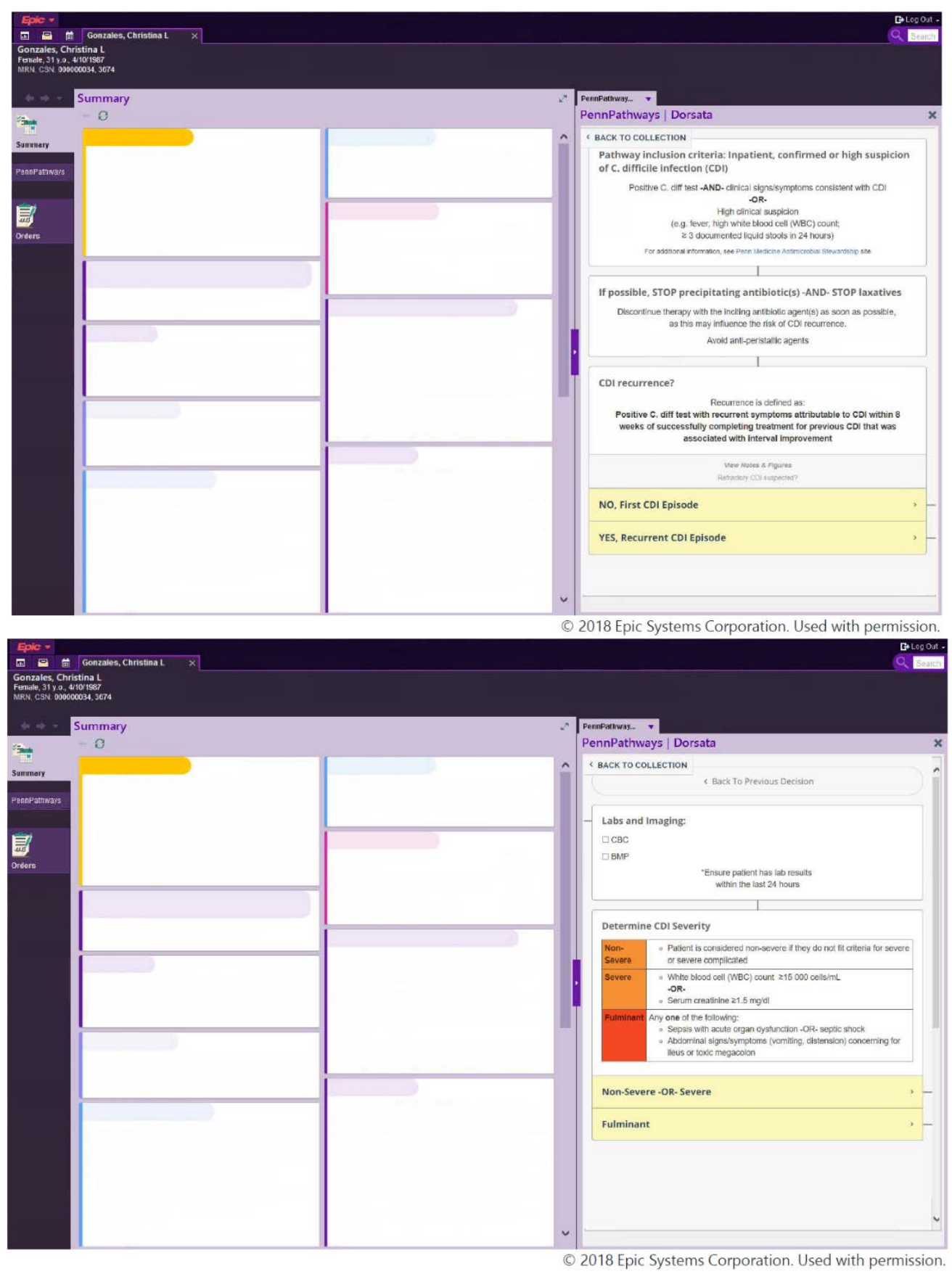